\title{
DOES THE UNCANNY VALLEY EXIST? AN EMPIRICAL TEST OF THE RELATIONSHIP BETWEEN EERINESS AND THE HUMAN LIKENESS OF DIGITALLY CREATED FACES.
}

\author{
by \\ Tyler Burleigh \\ B.A.H., Bishop's University, 2009 \\ A thesis submitted to \\ the Faculty of Graduate and Postdoctoral Affairs \\ in partial fulfillment of the requirements for the degree of \\ Master of Arts \\ in \\ Psychology
}

Carleton University

Ottawa, Canada

(C)2011 Tyler Burleigh 
Library and Archives Canada

Published Heritage Branch

395 Wellington Street Ottawa ON K1A ON4 Canada
Bibliotheqque et

Archives Canada

Direction du

Patrimoine de l'édition

395, rue Wellington

Ottawa ON K1A 0N4

Canada
Your file Votre référence
ISBN: $978-0-494-83145-8$
Our file Notre référence
ISBN: $978-0-494-83145-8$
NOTICE:

The author has granted a nonexclusive license allowing Library and Archives Canada to reproduce, publish, archive, preserve, conserve, communicate to the public by telecommunication or on the Internet, loan, distribute and sell theses worldwide, for commercial or noncommercial purposes, in microform, paper, electronic and/or any other formats.

The author retains copyright ownership and moral rights in this thesis. Neither the thesis nor substantial extracts from it may be printed or otherwise reproduced without the author's permission.
AVIS:

L'auteur a accordé une licence non exclusive permettant à la Bibliothèque et Archives Canada de reproduire, publier, archiver, sauvegarder, conserver, transmettre au public par télécommunication ou par l'Internet, prêter, distribuer et vendre des thèses partout dans le monde, à des fins commerciales ou autres, sur support microforme, papier, électronique et/ou autres formats.

L'auteur conserve la propriété du droit d'auteur et des droits moraux qui protège cette thèse. $\mathrm{Ni}$ la thèse ni des extraits substantiels de celle-ci ne doivent être imprimés ou autrement reproduits sans son autorisation.
In compliance with the Canadian Privacy Act some supporting forms may have been removed from this thesis.

While these forms may be included in the document page count, their removal does not represent any loss of content from the thesis.
Conformément à la loi canadienne sur la protection de la vie privée, quelques formulaires secondaires ont été enlevés de cette thèse.

Bien que ces formulaires aient inclus dans la pagination, il n'y aura aucun contenu manquant.

\section{Canadä}




\begin{abstract}
The uncanny valley theory (Mori, 1970) predicts a non-linear relationship between human likeness and emotional response. The emotions involved have been operationalized as eeriness and may relate to fear, disgust, and attractiveness. Empirical research on the uncanny valley theory has been inconclusive, as methodological difficulties have led to inconsistent results. The two goals of this thesis were to empirically test the uncanny valley theory and explore the nature of eeriness. 164 participants judged the human likeness, eeriness, scariness, disgustingness, and attractiveness of digital human face stimuli that varied on prototypicality and realism. Linear relationships were observed between human likeness and all emotional responses, while eeriness was found to be most strongly related to fear. These results may be interpreted to suggest that the primary assumption of the uncanny valley theory is incorrect and that eeriness is primarily related to threat avoidance or terror management processes.
\end{abstract}




\section{Table of Contents}

Title Page

Abstract

$\begin{array}{lll}\text { Table of Contents } & \text { iii-iv }\end{array}$

List of Tables $\quad v$

List of Figures

List of Appendices vii

$\begin{array}{ll}\text { Introduction } & 1-24\end{array}$

The Uncanny Valley $1-5$

Previous Research on the Uncanny Valley 5-11

Human Likeness and Eeriness $\quad$ 11-23

What is Human Likeness? $11-13$

What is Eeriness? $\quad 13-23$

Theories of eeriness. 13-23

Eeriness as cheater detection. $\quad$ 15-16

$\begin{array}{ll}\text { Eeriness as disease avoidance. } & 16-17\end{array}$

$\begin{array}{ll}\text { Eeriness as mate selection. } & 17-18\end{array}$

Eeriness as fear of death. $\quad 18-20$

Eeriness as fear: $\quad 20-21$

Eeriness as a combination of basic emotions. 21-22

Eeriness as cognitive dissonance. 23 
Summary

$\begin{array}{lr}\text { Present Experiment 24-44 } & \text { 24- }\end{array}$

$\begin{array}{lr}\text { Method } & 25-29\end{array}$

$\begin{array}{ll}\text { Procedure } & 29-31\end{array}$

$\begin{array}{ll}\text { Results } & 31-44\end{array}$

Evidence for the Uncanny Valley 31

The Relationship between Eeriness and Other Emotions . 43-44

$\begin{array}{lr}\text { Discussion } & 45-54\end{array}$

The Uncanny Valley $\quad 46-49$

$\begin{array}{ll}\text { Eeriness } & 49-51\end{array}$

$\begin{array}{ll}\text { Conclusions and Future Directions } & 51-54\end{array}$

$\begin{array}{lr}\text { Appendices } & \text { 55-68 }\end{array}$

$\begin{array}{lr}\text { References } & 69-77\end{array}$ 


\section{List of Tables}

Table 1. Measures of Central Tendency Obtained for Pre-Test Models.

Table 2. Linear, Quadratic, and Cubic Curve Estimations for the Relationship between Eeriness, Fear, Disgust, Attractiveness with Human Likeness, Separated by Stimulus Model.

Table 3. Pairwise Comparisons of Subjective Ratings between Each Model.

Table 4. Bivariate Linear Fits for the Relationships between Eeriness, Fear, Disgust, Attractiveness, Human Likeness with Protolypicality and Realism.

Table 5. Bivariate Correlation Matrix between Emotions.

Table 6. Stepwise Regression Analysis Predicting Eeriness from Fear, Disgust, and Attractiveness. 


\section{List of Figures}

Figure I The Uncanny Valley From "Buhımı no tanı [The uncanny valley]." by Morı. M . 1970. Energy. 7(4). p 33 Copyrnght 2005 by Karl F MacDorman and Takashı Minato

Reprinted with permission under the terms of the GNU Free Documentation License. Version 12

Figure 2 Stımulı Produced for Female 1

Figure 3 Shaded Crosstabs for Eeerness. Fear. Disgust. and Attractı eness Ratıngs across Human Likeness Ler els

Figure + Mean Eerıness Ratıngs across Human Likeness. Aggregated by Stımulus and Separated by Stımulus Model

Figure 5 Mean Fear Ratıngs across Human Likeness. Aggregated by Stımulus and Separated by Stımulus Model

Figure 6 Mean Disgust Ratıngs across Human Likeness. Aggregated by Stımulus and Separated by Stımulus Model

Figure 7 Mean Attractiveness Ratıngs across Human Likeness, Aggregated by Stımulus and Separated by Stımulus Model

Figure 8 Surface Plots for Mean Eeriness. Fear, Disgust. Attractiveness. and Human Likeness Ratıngs across Prototypicalıty and Realısm Lei els 


\section{List of Appendices}

Appendix A. Materials List for Pre-Test.

Appendix B. Parameters for Lighting and Staging Models in Blender 2.56.

Appendix C. Models Generated for Pre-Test.

Appendix D1. Parameters for Creating Prototypicality Levels in Poser 7.

Appendix D2. Parameters for the Poly Reducer Script in Blender 2.49.

Appendix D3. Polygon Counts for Each Model across Levels of Prototypicality and Realism.

Appendix E1. Stimuli Produced for Female 2.

Appendix E2. Stimuli Produced for Male 1.

Appendix E3. Stimuli Produced for Male 2.

Appendix F1. Subjective Measurement Scales.

Appendix F2. Example of an Experimental Trial.

Appendix F3. Informed Consent Protocol.

Appendix F4. Debriefing Protocol. 
Horror movies delıberately play on scary themes They portray danger, disease, and violence in order to arouse and eicite the audience Indeed these aspects can be considered the defining characteristics of the horror genre (Walters, 2004) When people watch horror movies. they expect to be shoched. disgusted and frightened The extent to which these experiences are realızed determines these films' success Naturally, no one would expect a holiday chıldren's movie to generate such reactions It is particularly interesting then when such a movie. The Polar Express (Zemeckis. 2004), can be cited as an example of incidental horror (Geller, 2008, Kloc, 2009, Levy, 2004. Loder. 2004) In this film, animated digital replicas of real human actors were used to attain a high degree of realism This anımation process consisted of capturıng the movement of a live actor and using this movement to direct a digital human The result has been halled by critıcs as "unnerıng" (Hanel. 2008). "creepıly unlıfelıke" (Keegan. 2009. p 235) and as having a "bızarre wax-museum qualıty" (Levy, 2004.p 1) Multıple authors have suggested that the near-perfect human likeness of the anımation was responsıble for people's negatıve reaction to it (e g, Bartneck. Kanda. Ishıguro, \& Hagıta, 2007. Chamınade. Hodgıns, \& Kaw ato. 2007. MacDorman. Green. Ho. \& Koch. 2009. Pollick. in press) This phenomenon is known as the uncanny valley

\section{The Uncanny Valley}

The uncanny valley theory describes how emotional reactions vary with perceived human likeness Mon (1970) onginally formulated the theory to describe people's reactions to robots. but it may be applied to anythıng possessing human-like qualitıes including digital anımation (e g , MacDorman et al , 2009) and voices (Tinwell \& Grımshaw, 2009) 
Figure 1 illustrates the theorized relationship between human likeness and emotional response. In this figure, the $y^{\prime}$-axis is labelled familiarity. an emotion with a positive valence. As the human likeness of a stimulus increases, an individual's emotional response to the stimulus becomes more positive, but when human likeness nears perfection, the individual`s emotional response sharply declines and becomes strongly negative. The area immediately following this decline is the uncanny valley. The two lines in this figure refer to the relationship between human likeness and emotional response separately, for still and moving stimuli. Mori (1970) speculated that motion would amplify both the positive and negative effects of human likeness because it provided additional information that could be used in evaluating the stimulus.

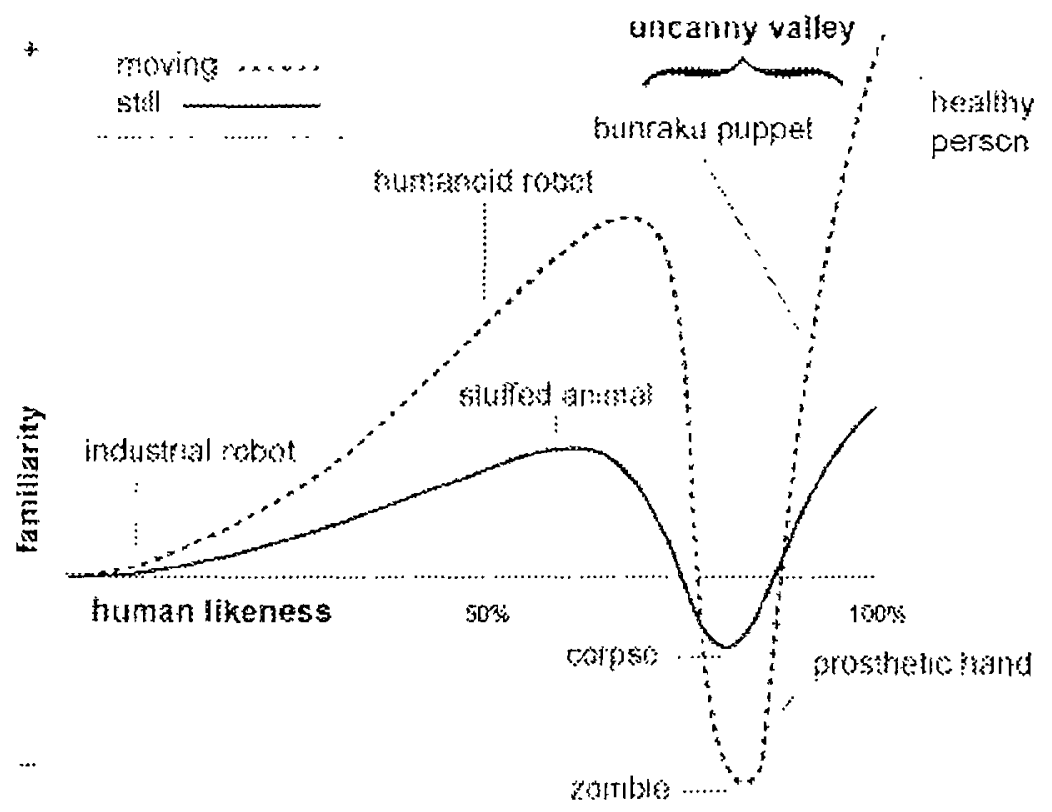

Figure 1. The Uncanny Valley. From "Bukimi no tani [The uncanny valley]," by Mori, M., 1970, Energy, 7(4), p. 33. Copyright 2005 by Karl F. MacDorman and Takashi Minato. Reprinted with permission under the terms of the GNU Free Documentation License, Version 1.2. 
The particular emotions thought to be involved in evaluating human-like stımul have varied considerably among authors Morı (1970) for example. used the term shinwakan which is Japanese for rapport (MacDorman et al .2009) to account for emotional responses Because rapport conveys feelıngs of "mutual trust" (American Hentage Dictionary, 2010b), this would imply that the emotion is of a social nature Feelings of mutual trust may increase up to nearperfect human likeness. at which point a person might feel distrust or suspicion The term appearıng in Figure 1, famillarity, has also appeared with some regularity (Bartneck. Kanda. Ishıguro. \& Hagita, 2007. Chaminade. Hodgıns. \& Kawato. 2007. Hanson, 2005. Ho. Pramono. \& MacDorman, 2008, MacDorman \& Ishiguro, 2006, MacDorman, 2005, MacDorman, 2006) Objects which are familiar are hnown to elıcit positıve emotions (Bornsteın, 1989) However. familianty does not necessanly increase with human likeness Hence, more human-like objects may be more familiar and less threatening than less human-like objects. but only up to nearperfect human likeness Most frequently, the emotional response has been characterized as eeriness, an emotion with a negatı e valence (Bartneck, Kanda, Ishiguro, \& Hagita. 2007, Chamınade, Hodgins. \& Kawato. 2007, Hanson. 2005, Ho, Pramono. \& MacDorman. 2008. MacDorman \& Ishiguro, 2006. MacDorman 2006. MacDorman Green, Ho. \& Koch, 2009. Steckenfinger \& Ghazanfar. 2009) The orıgin and meaning of eenness will be examined in a later section

Realism is obviously a desirable property for objects such as androids or human characters in movies and video games that are specifically designed to be convincingly human Therefore. designers have an impetus to improve the perceptual realism of media When perceptual realısm is increased, then believability and immersion are also improved (see 
McMahan, 2003). However, a lesson learned from The Polar Express (Zemeckis, 2004) seems to be that technological advances whıch facilitate greater levels of realism can have unintended negative consequences. Mori (1970) proposed one solution to this dilemma. He suggested that designers can avoid such backlash by deliberately limiting the amount of human likeness in their work, an approach he called "escape by design". This is an idea which, by some accounts, has already achieved a dogmatic status (p. 2. MacDorman, as cited in Kloc, 2009). For example, when filmmaker James Cameron explained to the Avatar (Laundau \& Cameron, 2009) movie computer graphics supervisors that they would be using a motion capture technique like the one used in The Polar Express (Zemeckis, 2004) to produce digital human-like characters, "it made them very uncomfortable, and they were fearful of it wrecking the company" (p. 236, as cited in Keegan. 2009).

Although the uncanny valley has generated interest in both scientific and professional communities, empirical support has been mixed. The main objective of my thesis ivill be to examine the primary assumption of the uncanny valley, namely that human likeness and emotional response display the non-linear relationship illustrated in Figure 1. The extant uncanny valley literature will be reviewed with an emphasis on methodology, particularly the manner in which human likeness has been defined. My goal will be to rigorously operationalize this construct in preparation for the present study. The second objective of my thesis will be to contribute to a better understanding of eeriness. Several theories have been proposed to account for this emotion in terms of cognitive and evolutionary frameworks. These theories will be reviewed in depth with an emphasis on the emotions thought to be related to eeriness. The present research will therefore measure subjective reports of eeriness as well as reports of 
emotions which have been associated with eeriness. These theories will then be tested by examining the relationships between emotions.

\section{Previous Research on the Uncanny Valley}

MacDorman and Ishiguro (2006) carried out the first empirical test of the uncanny valley theory. In this experiment, stimuli were generated by morphing robot and human faces at different levels (e.g., $25 \%$ robot and $75 \%$ human; $50 \%$ robot and $50 \%$ human). Two sequences of morphed images were generated in this manner (one female and one male). Participants were asked to rate these images using human likeness, familiarity, and eeriness scales. The images and scales were randomized to prevent order effects. For both male and female morphing sequences, human likeness ratings increased monotonically. As human likeness ratings approached a midpoint between machine-like and human-like, eeriness ratings increased and familiarity ratings decreased sharply. Thus, an uncanny valley trend was observed.

It can be argued, however, that these results are difficult to generalize for two reasons. First, the morphing process unintentionally generated atypical features. For example, in the male morphing sequence, a large black dot appears on the centre of the robot's forehead. When this robot's image was morphed with the human-like image, the black dot was preserved in some of the morphed stimuli. Although such a feature may not be disturbing when seen on a robot, there are interpretations that could cause negative affect when seen on a human (e.g., bullet hole, tumour, third eye...). This explanation is supported by the fact that the levels where this feature appears are also those which produced an uncanny valley. It is therefore difficult to assign with certainty the cause of the uncanny valley: subjective human likeness or the atypical feature. Second, the results may be difficult to generalize because both the stimuli and the subjective 
measure of human likeness involved not only human likeness, but also machine likeness. That is, stimuli were generated from two unique prototypes (human. robot) and the scales probed for ratings that were related to two distinct categories (human, machine). If these conditions elicited mutually exclusire categorical evaluations, then this may have caused cognitive dissonance. Cognitive dissonance is a state which is itself thought to cause feelings of discomfort (Elliot \& Devine, 1994). Thus, individuals may have responded negatively not because the stimuli possessed a given level of human likeness, but because experimental conditions unintentionally aroused cognitive dissonance.

In a related study, Seyama and Nagayama (2007) selected faces of dolls to represent low human likeness, and as before, morphed these images with human faces. Unlike MacDorman and Ishiguro (2006), images entered into the morphing process did not appear to possess any atypical features. Another important difference was that participants were not asked to rate human likeness. Instead, human likeness was determined by the position of an image in its morphing sequence. For instance, a half-doll, half-human image was assumed to possess $50 \%$ human likeness. Emotional responses were measured with a pleasantness scale. Results from this experiment did not reveal an uncanny valley. The authors nevertheless dismissed this negative finding for methodological reasons. They argued that the range of realism afforded by their stimuli was not sufficiently large for an uncanny valley to emerge.

Consequently, Seyama and Nagayama (2007) expanded the range of realism in a followup experiment. They modified the stimulus creation process such that the face and the eyes were morphed at different rates. That is, in one sequence, all doll features except the eyes were morphed into human features in $20 \%$ increments after which the eyes were then morphed in $20 \%$ 
increments. In a second sequence. Seyama and Nagayama used a similar procedure to morph the eyes first and then the rest of the face. The results showed that an uncanny valley pattern emerged when pleasantness ratings were plotted across the morphing sequence. Once again, however, interpretation issues arose. It was observed that pleasantness ratings were lowest when the facial features were mismatched (e.g., doll eyes on a human face or human eyes on a doll face). The uncanny valley phenomenon may therefore have been caused by mismatched realism across levels of human likeness. Alternatively, mismatched realism at higher levels of human likeness may also be seen as having produced atypical features on otherwise typical human figures. Therefore, these results are open to two interpretations. One interpretation would designate mismatched realism as the cause of eeriness at higher levels of human likeness. Another interpretation would identify the mismatched realism as a more general case of violating normative expectations for humans. In the latter case, one would expect to find similar results under conditions where stimuli possess other unusual features. Importantly, neither case allows the authors to safely attribute the results to the uncanny valley; that is, the stimuli's placement on a continuum of human likeness.

Seyama and Nagayama (2007) therefore conducted an additional experiment to test the second interpretation of their results. In this experiment, mismatched stimuli were not used. Instead, an atypical feature (i.e., large eyes) was introduced across levels of human likeness. Stimuli were made to vary along human likeness as in the first experiment, and eye size rvas also increased to $150 \%$ at each level. An uncanny valley was found when relating pleasantness to human likeness. These findings suggest that that eeriness at higher levels of human likeness may be caused because stimulus features deviate from expectations. In other words, higher levels of 
human likeness may serve to increase sensitivity to violations of normative human appearances Thus, the presence of an atypical feature may be a necessary condition for the emergence of an uncanny valley.

The reviewed studies up to this point have all used still images to test the uncanny valley theory. Mori (1970) had predicted, however, that moving stimuli would be even more effective in eliciting the phenomenon. Indeed, animated stimuli provide an even richer set of cues to evaluate the human likeness of given stimulus. For example, facial expressions or certain bodily gestures can reflect internal mental states that are uniquely human. Therefore, providing this additional source of information raises the extent to which an object can believably simulate a human, while also raising the degree to which expectations can be violated. As a result, according to the uncanny valley theory, animated human-like figures should produce stronger positive and negative emotional reactions. To test this hypothesis, MacDorman (2006) collected fourteen 3060 second video clips. Thirteen depicted a variety of robots at varying levels of sophistication and one depicted a human. These clips were presented to participants who provided ratings of human-likeness, familiarity, and eeriness. Contrary to Mori's predictions (1970), no uncanny valley was found. Given the variability of the stimuli, one might speculate that the participants were attending to different features of the stimuli, which in turn impacted the ratings. Thus, using a more rigorously controlled experiment, an uncanny valley might still have been found.

It can be argued that the studies described so far have had problems generating stimuli that vary in human likeness while excluding extraneous features that would allow for a clear interpretation of the results. More recently, MacDorman et al. (2009) conducted a test of the uncanny valley theory that addressed this difficulty. Unlike previous studies which sometimes 
introduced atypical features by blending images together, digital human models were used and modified directly to produce multiple levels of human likeness. The highest level was the original source image, and lower levels were created by reducing the texture and geometric realism of the model. In two experiments, participants rated these stimuli on human likeness and eeriness scales. As expected, subjective human likeness increased in a linear fashion with increasing realism. Contrary to the predictions of the uncanny valley theory, however, there was also a linear relationship between human likeness and eeriness.

To better understand how realism and human likeness are related, MacDorman et al. (2009) conducted a second experiment in which participants were asked to adjust stimulus parameters at each level of realism to make them "look best". Stimulus parameters included the separation of eyes and the height of the face. The results showed that at higher levels of realism, faces that were created by participants were proportionally closer to the original face than those at lower levels of realism. This finding suggests, in line with Seyama and Nagayama s (2007) results, that realism might produce an increased sensitivity to deviations from human norms. The authors speculated that this could be due to human-specific evaluative processes which are activated only when the stimulus reaches a certain level of human likeness.

This possibility was examined in a final experiment. In this experiment, the effects of mismatched realism and the presence of an atypical feature on subjective ratings were examined. Two sets of images were produced. Across both sets of images, the texture realism of the model's skin and eyes were manipulated separately by selectively blending these features of the textured model with an untextured version of the same model. For one set of images, the size of the eyes was also increased by 50\%. Participants rated the eeriness, naturalness, and attractiveness of 
these images The results did not produce an uncanny valley It was observed that models were most eerıe at $100 \%$ eye testure realısm and $0 \%$ shın realısm least eerıe at $75 \%$ shın realısm and $50 \%$ ey e texture realısm and that the enlarged ey es uniformly increased negative reactions across levels of realısm These findings do not support the sensitısity hypothesis The authors concluded that stımuli might have not have had a sufficient level of human likeness to create the uncanny valley Such a conclusion however, is difficult to sustain drawing upon this single null finding

One shortcoming of MacDorman et al s (2009) study is that all stımulı were denved from a single human model It is possible that properties unique to this model were responsible for the relationship observed between human likeness and emotional response Therefore, it is problematıc to estrapolate from these findings to all possible models or to human likeness in general Nevertheless, MacDorman et al designed a methodology which allows the researcher to manipulate human likeness in a precise and systematıc fashion Thus. an estension of this paradıgm and a replication of these findıngs would appear to be the next logical step in examuning the uncanny valley theory

In conclusion, there has been mised evidence for the uncanny valley Two studies reported here have observ ed the phenomenon (MacDorman \& Ishıguro, 2006, Seyama \& Nagayama. 2007 Experiments 2, $3 \&$ 4) and three others have not (Seyama \& Nagayama, 2007, Experıment 1 MacDorman. 2006, MacDorman et al . 2009) Additional studies found in the literature but not reported here have also been mised, with at least three more finding support (Bartneck et al . 2007. Schneider et al . 2007, Stechenfinger \& Ghazanfar, 2009) and one more unable to find support (Hanson. 2005) As I have argued. many of these studies both for and 
against the theory have had methodological difficulties (MacDorman, 2006: MacDorman et al., 2009; MacDorman \& Ishiguro, 2006; Seyama \& Nagayama. 2007). If a definitive test of the uncanny valley theory is to be conducted, then these issues first must be resolved. Therefore, in the sections to follow. I will consider the constructs of human likeness and eeriness in more detail in order to design the methodology for the present experiment.

\section{Human Likeness and Eeriness}

In these sections, Hanson's (2005) definition of human likeness and MacDorman et al. 's, (2009) theories of eeriness will be reviewed. These concepts will be discussed in depth, and will be used to guide the definitions and methods to appear in the experiment that follows.

\section{What is Human Likeness?}

Human likeness is the degree to which an object is perceived to possess human-like appearance and behaviour. It is therefore a subjective judgment. In the uncanny valley literature, it has been measured with Likert and semantic differential scales. For example, MacDorman and Ishiguro (2006) used a scale anchored by "very humanlike" and "very mechanical". Human likeness can also be viewed objectively as a set of stimulus properties. Hanson (2005) provided one such objective definition. This definition appears to obviate some of the methodological concerns that have been discussed, and may help guide the operationalization of human likeness with computer graphics and robotics. Hanson suggested that human likeness should only be relative to those elements which a human naturally possesses:

"human likeness is being within the possible, naturally-occurring appearance of real human beings... [the] sub-characteristics of realism, such as physical geometry, texture, and coloration... [which] will be constrained by human biology" (p. 3). 
Defined in this way. human likeness refers only to properties of objects which are human in origin Therefore. scales like MacDorman and Ishıguro`s (2006) which presented human likeness as a human-machine dichotomy would not be appropriate With respect to the operationalization of human likeness. the hey term in this definition is realism Tautologically, a real human being possesses perfect realısm

Realism may best be understood in terms of the technology used to generate human likeness Computer artısts, for example. can generate digital humans at vanous specifications depending on the software and hardware used As computer technology has progressed, artists have been able to increase human likeness by developing models with more detal Consistent with Hanson's (2005) definition, the amount of detall that a digital human possesses can be summed up by two properties texture resolution and poly gon count Texture resolution refers to the amount of information that can be represented by a single surface of a $3 \mathrm{D}$ model It is similar to the number of pixels that a digital camera can capture or that a computer monitor can display At a minimum resolution. it is only possible to represent a surface by a single colour As resolution increases, more particularities can be introduced into the surface of an image At higher levels, features like skın pores, veins, wnnkles, or millions of individual hairs are possible to represent Polygon count refers to the number of polygons in a 3D model These allow computer models to approximate the true shape of an object, such as the human form A single polygon is a shape, such as a square. whıch is used as a sıngle surface of a $3 \mathrm{D}$ object A cube. for example. is a $3 \mathrm{D}$ object with a six polygons As the shape of an object becomes more intncate. the number of polygons required for approximation increases dramatically As texture resolution and polygon count increase. the memory and time requirements for processing an image will 
increase. and so there is a limit imposed by the avallability of these processing resources Using this same technology. it is possible to reduce detail - and therefore human likeness - in a precise and controlled manner by reducing texture resolution and/or polygon count This is the strategy that will be used to generate the stimuli in this thesis

\section{What is Eeriness?}

Dictionaries hav e defined eeriness in several ways For example one definition is that eerıness is a reaction to something "so mysterious, strange. or unerpected as to send a chill up the spine" (Mernam-Webster, 2010) Another definition is that it is "inesplicable fear. dread, or uneasiness" (American Heritage Dictionary, 2010a) But by far the simplest definition is that eerıness is caused by somethıng that is both "strange and fnghtenıng" (American Heritage Dictionary, 2010b)

As these definitions make clear, eerıness is an emotional reaction to a stımulus How ever. one may wonder whether eenness is synonymous with one or more existıng emotions, such as fear Several theones have been proposed to explain what eerness is. relatıng it to multiple emotions Another consideration. therefore is whether eeriness can be decomposed into more than one emotion These theories are primanly grounded in evolutionary and cognitive frameworks The following sections will examine these theories They will help guide the present research, whıch will seek to further explore the nature of eenness

Theories of eeriness. Before launching into the theories, some general considerations ivill first be addressed One consideration is that the plausibility of ser eral of these theones rests on the assumption that eeriness is related to basic emotional or cognitive processes Based on this assumption, it might be expected that the uncanny valley phenomenon would be observed in 
other intelligent species. Steckenfinger and Ghazanfar (2009) conducted an experiment to examine this possibility. In this study, macaque monkeys were shown three stimuli varying in monkey likeness: one real monkey face, one high realism computer model that approximated the real monkey face, and a second low realism computer model with reduced texture and polygon count. As is common with subjects that cannot provide subjective reports, affect was inferred from gaze frequency and duration. Longer and more frequent gazing was taken as a sign of comfort or attraction and therefore positive affect, whereas shorter and less frequent gazing was taken as a sign of discomfort or aversion and therefore negative affect. The authors found that monkeys gazed longer and more frequently at the photograph and the unrealistic model, and displayed relatively less long and frequent gazing with the realistic model. The authors speculated that the uncanny valley might therefore be related to the social processing of conspecifics.

Another general consideration is just how this processing might occur. There is evidence to suggest that human infants at 6 months of age are able to discriminate between faces of different species, and at 9 months, they begin to discriminate among individuals within a species (Pascalis, Haan, \& Nelson, 2002). Because humans are exposed to many conspecifics over the course of a lifetime, an expertise for discrimination is developed which sensitizes individuals to visual and social norms, and consequently, deviations from these norms. Specific regions of the brain which are responsible for such processing have been identified. The Fusiform Face Area, for example, is an area of the fusiform gyrus which appears to selectively process faces (Kanwisher, McDermott, \& Chun, 1997). It is activated with an equal strength by real faces and by cartoon caricatures of humans (Tong, Nakayama, Moscovitch, Weinrib, \& Kanwisher, 2000). 
Similarly, a different area of the fusiform gyrus has been observed to be activated by the abstract representation of the human body as stick figures (Peelen \& Downing, 2005). Such specialized areas would be involved in the processing of human-like figures. Depending on subjective human likeness, these areas are likely to be activated to different degrees. If it can be assumed that certain other systems are preferentially wired to these regions of the brain, then these subsystems might only be activated at higher levels of human likeness. In other words, a category boundary for human-likeness might exist such that relevant sub-systems are only activated beyond a threshold. These sub-systems might involve monitoring processes that are sensitive to social cues like deception, signs of disease (i.e., systems that elicit disgust and aversive reactions, see Oaten, Stevenson, \& Case, 2009), or signs of reproductive fitness (i.e., systems that elicit feelings of sexual attraction, see Rhodes, 2006). In the context of the uncanny valley, such stimuli may then be sufficiently high in human likeness to activate human evaluative processes, and may possess features or defects that elicit negative emotions because they appear to be cheaters, disease carriers, or unsuitable reproductive partners. Thus, theories relating eeriness to cheater detection, disease avoidance, and mate selection appears to be plausible.

Eeriness as cheater detection. When people say "Sam gives me the creeps," they mean that Sam seems suspicious or untrustworthy. This idea that eeriness is fundamentally related to trust was discussed earlier in terms of rapport. I believe that this idea can be further specified if the social utility of trust is considered. According to Trivers (1971), humans have evolved a class of behaviours known as reciprocal altruism. Reciprocal altruism involves one individual performing a favour for another with the implicit expectation of a future return. Given that the individual performing the favour is vulnerable to others who may selfishly exploit the situation, 
evolution must also have selected for the ability to detect and avoid such cheaters. Verplaetse, Vanneste, and Braeckman's (2007) recent study provides support for this theory. They photographed the faces of individuals playing the prisoner's dilemma game. This game involves placing two individuals in a situation where one individual's outcome depends on their choice as well as the other player's choice. However, individuals are not told the other player's choice until both players have made a decision. A decision involves either cooperating with or cheating on the other player. If one player cheats and the other cooperates, then the individual cooperating loses and the cheater wins. If both players cheat, then they both stand to lose. However, if both players cooperate, then they both win. Although winning through mutual cooperation yields slightly less individual gain than winning by cheating, an individual stands to gain even less from a mutual cheating outcome. Verplaetse et al. photographed their participants at the instant that a decision was made to cooperate or cheat. Other participants were then shown these photographs and asked to predict the decision. It was observed they were able to predict when someone had decided to cheat with greater than chance accuracy. Verplaetse et al. suggested in agreement with Trivers' theory that these predictions were based on heuristics with a subjective component that can be described as feelings of trustworthiness or suspicion which evolved for the purpose of cheater detection and avoidance. If eeriness is primarily an emotion involved in deciding whether or not to trust a conspecific, then by extension, it might be vieved as an evolutionary mechanism for avoiding cheaters.

Eeriness as disease avoidance. Disgust is an evolutionary adaptation to the challenges imposed on our ancestors by parasites and pathogens (Thorrthill \& Gangestead, 1993). It is an emotion aroused by cues indicating a threat of contamination. For example, the visible signs of 
leprosy are perceived as a contaminatıon threat and thereby elıcit disgust However, there are also non-contaminatıng conditıons that will arouse disgust. such as facial disfigurement or physical disabilities resultıng from accidents It has been argued that these non-contagious stımulı will elicit disgust due to the hyper-vigilance of our threat detection system (Park Faulkner, \& Schaller. 2003) This system. owing to its role in motwating survival behaviour, has a tendency to make false positıves ( 1 e . evaluatıng a stımulus as being a contamination threat when in fact it is not) because such sensituvity has been adaptive It is therefore possible that deviations from human feature norms could, due to the sensilivity of this system, be perceived as contagions and elicit disgust If eerness is related to disgust. as at least one study suggests ( $\mathrm{Ho}$ Pramono. \& MacDorman. 2008), then it might also be related to disease avoldance processes Eeriness as mate selection. Attractiveness is a process that has been explaned by evolutionary theory as serving mate selection and reproduction Attractiveness acts as a proxy for signalling biological and reproductive fitness (Rhodes. 2006) It has been argued that there are three universal standards of beauty sy mmetry, ar erageness and sexual dimorphism (Rhodes, 2006, Thorrthill \& Gangestead, 1993, Langlors, 1990, Langlors, Roggman, \& Musselman, 1994) With respect to faces. symmetry refers to the similarity of features on each side of the midline and averageness is the degree to which the face resembles the mean of the population of faces ( $1 \mathrm{e}$, its prototypicality) Sexual dimorphism refers to specific traits that develop in individuals who are extremely biologically fit (so fit, in fact. that they handicap therr own immune system in the process, see Thornthill \& Gangestead, 1993) Examples of dimorphic traits are raised cheekbones in females and a square chin in males (Thornthill \& Gangestead, 1993, Rhodes, 2006) 
Attractiveness may be an important consideration for establishing whether evaluations of real human stimuli rely on the same internal criteria as artificial human-like stimuli. It is implied by the evolutionary account that attractiveness is to some degree of a sexual nature. Halberstadt (2006) provides an alternative explanation, which accounts for attractiveness in terms of categorization processes. On his view, any stimulus is attractive if it is highly prototypical and becomes less attractive as it deviates from this norm. As discussed previously, categorization may be an important consideration with human-like stimuli, because humans are particularly sensitive to their orvn species. The degree of human-likeness of a stimulus may determine if human-specific evaluative processes are recruited. In this way, attractiveness may have several meanings: one being asexual for non-human objects and another being sexual for other humans who are potential reproductive partners. Consequently, depending on realism, it is possible that human-like stimuli may be evaluated in two fundamentally different ways with respect to attractiveness. If eeriness is strongly related to attractiveness, as has been observed (Ho, Pramono, \& MacDorman, 2008), then it might be caused in part by mate selection processes.

Eeriness as fear of death. Mori (1970) supposed that uncanny human-like robots resemble the dead because of their skin discolouration, cold temperature, and stiff movement. He further suggested that this resemblance was a general property of uncanny stimuli and that it activated a fear of death. MacDorman and his colleagues (MacDorman \& Ishiguro, 2006; MacDorman et al., 2009) have since expanded on this theory with the support of a social psychology framework called Terror Management Theory (TMT). According to TMT, all human behaviour is motivated by the fear of death, which is mediated by a person's self-esteem and beliefs that sustain a sense of "symbolic immortality" (Amdt, Greenberg, Pyszczynski, \& 
Solomon. 1997; Burke, Martens, \& Faucher, 2010). Beliefs about the world, such as religious or cultural worldviews, are responsible for this mediation. These beliefs create the illusion that the world, and by extension the individual's existence, is stable and meaningful. Such beliefs often give meaning to non-existence itself (e.g., religious ideas about the "afterlife"). However, when individuals are reminded of their mortality, this illusion is threatened and they react by reaffirming the beliefs which sustain the illusion. For example, individuals will evaluate in-group persons more positively, and out-group persons more negatively (Greenberg, Pyszczynski, Solomon, \& Rosenblatt, 1990). MacDorman (2005) provided support for the hypothesis that uncanny stimuli elicit a fear of death. In this study, participants were presented with an image of a human or an android and then asked to read two statements written by hypothetical foreign students who lived in the participants' home country. One of the foreign students' statements praised the country and the other denigrated it. Thus, one of these statements can be viewed worldview-supporting, and the other as vorldview-threatening. Participants were also asked to complete a death cognitions measure. It was observed that those who vieved the android both showed a preference for the worldview-supporting statement and a greater activation of deathrelated thoughts, than those who viewed the human.

Fear of death may also be related to disgust as has been observed in at least two studies. In one study, Haidt, Mccauley and Rozin (1994) presented participants with a variety of disgusting items. They then measured disgust and fear of death using separate scales. It was observed that the two scales were moderately correlated. Moreover, this correlation held even when items on the disgust scale relating to death were partialed out. More recently, Cox, Goldenberg, Pyszczynski and Weise (2007) performed a study where participants were made to 
look at images such as a dirty tollet. feces. or vomit They were then ashed to report on feelings of disgust and to complete an unconscious measure of fear of death ( 1 e. word fragments such as "G R A E E") It was observed that thoughts of death increased for those individuals viewing the disgusting 1mages, but not for those in the control condition An association between fear of death and disgust suggests that if eerie images elicit a fear of death, then disgust may mediate this response This would be the case if eerie images are disgustıng. but do not actually resemble a dead person. and therefore do not directly activate thoughts of death

MacDorman et al (2009) also suggested that eerie stımulı may actıvate fear of death by reminding individuals that human are biological machines Related to this suggestion, Cor et al (2007) primed participants with one of two ideas humans are just another kind of animal or humans are unique and superior to anımals When mildly disgustıng stımulı were presented. a fear of death $w$ as obser ed among those primed to think humans are anımals Therefore. even if a human-like stimulus is only mildly disgusting, it may still activate a fear of death if it serves as a reminder of human as biological entıties Because the present research will measure fear. the nature of subjective fear reports is an important consideration Determining the nature of this fear, however. 1s beyond the scope of the present thesis

Eeriness as fear: The fear of death must be contrasted with what is commonly considered fear Ordinary fear is a physiological response to a physical threat (1 e , the fight-or-flight response) A fear of death, however. has not been observed to elicit any physiological response at all (Greenberg, Pyszczynskı, Solomon. Simon. \& Breus, 1994) Accordıng to Greenberg et al (1994). experimental conditions used to elicit fear of death have "consistently falled to produce negatıve affect. anvety. or phy siological arousal"' ( $p$ 627) In contrast. a visceral fear is caused 
by perceived physical threats and manifests as negative affect, anxiety, and physiological arousal. It is clear that these two kinds of fears are distinct. Therefore, if eeriness is related to fear, then the next question is what kind of fear?

Eeriness as a combination of basic emotions. The theories presented so far suggest that eeriness may be accounted for in terms of other emotions, particularly fear, disgust, and attractiveness. Ho et al. (2008) designed a study to examine the relationships eeriness has with other emotions. Participants were presented with short video clips of robots at different levels of realism. For each video, they were asked to rate their emotional response on 27 different scales. Several analyses were performed to determine the variance explained in eeriness. First, a regression analysis revealed that the 27 emotions accounted for $62 \%$ of the variance in eeriness, but only 5 were necessary to account for $60 \%$. These five emotions were fear, disgust, nervousness, dislike, and shock. Next, a factor analysis was performed revealing that two factors explained $43 \%$ of the variance in ratings. According to factor loadings, the first factor was formed in part by emotions such as fear and disgust, while the second factor was formed in part by attractiveness. Finally, a multi-dimensional scaling analysis revealed that eeriness was closely related to fear and disgust. Thus, it appears that the relationships among eeriness, fear, disgust. and attractiveness merit further examination. It is also important to consider that eeriness may not relate exclusively to one of these emotions, but instead may relate to multiple emotions. Specifically, eeriness may emerge from their combination and thus be classified as a complex emotion.

There is a precedent for classifying emotions based on their complexity. For example. emotions such as fear and disgust are considered to be basic units of emotion (Ekman, 1994; 
Plutchik, 1962. Turner, 2000) This classification is based on cont erging evidence for the distınctive physiological patterns and univ ersal signals of human facial eipression associated w1h these emotions It has been suggested that when these basic emotions are mixed. they can produce complex emotions Plutchih (1962). for example, proposed that just as chemicals can be combined in limited ways to form compounds. basic emotions may combine to form complex emotions (e g, fear + sorrow $=$ desparr, or disgust + espectancy $=$ cynıcısm $)$ In a related account. Turner (2000) described a model of human emotion based on four emotion modules correspondıng to satısfaction-happiness. assertion-anger. aversion-fear, and disappointmentsadness These modules are actir ated with varying intensity, which in turn can be described as vanations on basic emotions For example, the emotion of fear can be described by the aversionfear module a high level of activation could be described as feeling hornfied, while a low level of activation could be described as feeling shy Emotions can also be mixed because these modules are independent and can be actur ated sımultaneously. thus giving rise to second-, thirdor fourth-order complex emotions For example. mixing particular intensities of assertion-anger with disappointment-sadness could give rise to feelıng betrayed. or miving aversion-fear with assertion-anger could give nse to revulsion It seems plausible. therefore, to suppose that emotions like fear. disgust. and attraction could combine to form a complex emotion such as eerıness In terms of Plutchık's (1962) model, this is a straightfonvard combination (e g . fear + disgust - attraction $=$ eerıness) Under Turner's (2000) model, the combination is more challenging to specify, but would likely involve the aversion-fear, assertion-anger and/or disappointment-sadness modules 
Eeriness as cognitive dissonance. In context of the uncanny valley, human-like objects may appear to simultaneously belong to multiple categories. For example, in the design of human-like robots, the design may possess some attributes that are highly typical of a human and others that are highly typical of a machine. Such an object might then be categorized as both human and non-human. When two conflicting ideas are held simultaneously, this causes cognitive dissonance. Like eeriness, cognitive dissonance is thought to create feelings of discomfort and uneasiness (Elliot \& Devine, 1994). Some have suggested (e.g., Ho et al,, 2008; MacDorman et al., 2009; Pollick, in press) that eeriness might therefore be an interpretation of the physiological response which is accompanies this conflict.

\section{Summary}

According to the uncanny valley theory, emotional reactions become more positive as human likeness increases, but only up to a point after which emotional responding becomes negative. To date, empirical research on the theory has found mixed results. Although it has been adopted by many in the computer graphics and robotics industries, a strong case cannot yet be made for its validity.

The operational definition of human likeness used in some studies, such as MacDorman and Ishiguro (2006) and Seyama and Nagayama (2007), involves morphing humans with humanlike objects of another category such as robots and dolls, respectively. I have argued that this makes these experiments' conclusions difficult to generalize because such a process may be inadvertently introducing cognitive dissonance or other confounds. A definition of human likeness has been proposed (Hanson, 2005), which I have argued is generalizable to both computer graphics and robotics. This definition constrains stimuli to the human category of 
objects and allows for variance in terms of stimulus parameters that are naturally found with human-like objects, such as geometry and texture. This definition appears consistent with MacDorman et al. 's (2009) experimental approach. Therefore, MacDorman et al.'s (2009) paradigm will be modified and extended in the present thesis in order to create a stimulus set whose relation to eeriness and other emotions can be unambiguously interpreted.

Finally, the emotional reactions elicited by stimuli across levels of human likeness are not well understood. It is likely that multiple emotions are involved, and based on the literature, it appears that fear, disgust, and attractiveness may be particularly dominant emotional reactions. Eeriness has become synonymous with the subjective experience that uncanny stimuli arouse in individuals. However, the nature of eeriness is unclear. Therefore, this study will attempt to determine which emotional reactions are aroused in individuals by stimuli varying in human likeness. If an uncanny valley phenomenon is observed, then emotional reactions to stimuli which fall into the uncanny valley will be examined as well.

\section{Present Experiment}

To test the uncanny valley theory, four human computer models will be manipulated along two human likeness dimensions, prototypicality and geometric realism. Additionally, subjective reports of human likeness and emotional responses will be obtained. In particular, eeriness will be measured as it is thought to uniquely characterize the affect produced by uncanny stimuli. If the uncanny valley theory is true, then human likeness and eeriness should be related in a non-linear fashion. Specifically, this relationship should be cubic (See Figure 1). Fear, disgust, and attractiveness will also be measured. If the uncanny valley theory is true, then these emotions should also demonstrate a cubic relationship with human likeness. If, however, a 
linear relationship is observed between human likeness and any of the four emotional ratings, then this will cast doubt on the primary assumption of the theory and bring into question the validity of the theory itself.

Hypotheses were also made regarding the relationship between eeriness and fear, disgust, and attractiveness. Several competing theories regarding the nature of eeriness will be tested as follows. If eeriness is related to disease avoidance processes, then it should be strongly correlated with disgust. If eeriness is related to mate selection processes, then it should be strongly correlated with attractiveness. If eeriness is related to physical threat detection and/or terror management, then it should be strongly correlated with fear. Finally, if eeriness is a complex emotion, then it should be strongly correlated with multiple emotions. Based on previous findings, it is expected that eeriness and fear will generate the strongest relationship followed by disgust and then attractiveness.

\section{Method}

\section{Participants}

164 undergraduate students ( 79 males, 85 females, $M_{\text {age }}=20.4$, age range: $17-43$ years) were recnited through the Carleton University Sona online experiment management system. Participants were compensated with bonus marks towards an introductory Psychology course.

\section{Materials}

Stimuli. A pre-test was conducted to select computer-generated faces perceived to be attractive for the main experiment. This was necessary to ensure that average, and therefore representative faces, would be used. 80 participants ( 54 females, 26 males, Mage $=19.8$, age range $=17-37$ years) who were different than those involved in the main experiment were 
recruited from Carleton University using the Sona experiment management system. They were compensated with bonus course marks if they were eligible. The stimuli consisted of 16 computer models ( 8 female and 8 male) that were purchased from Daz $3 \mathrm{D}$ (n.d.) and Renderosity (n.d.) digital artist communities. These models included 3 "base" models, Victoria 4.2 (V4), Michael 4 (M4), Stephanie 4 (S4), and a variety of derivatives that modified the anatomy and textures of these base models. Derivative models included Amy for V4, Asami for V4, Beach Boy for M4, Eastem Girl for V4. Girl Next Door 4 for V4. Lee for M4. Marie for V4, Muchacho for M4, Raphael for M4, Rio for V4. Rob for M4, Sol for M4. and Spartacos for M4 (See Appendix A for a materials list with sources).

In order to generate the final appearance of stimuli, two pieces of software were used: Poser and Blender. Models were purchased in a native file format for Poser 7 In order to maintain consistent appearance between the pre-test and the main experiments, models were exported from Poser in the Wavefront .obj file format and imported into Blender 2.56 for staging, lighting, and final processing. Models were each staged using a three-point lighting technique (a traditional lighting used in studio photography and with 3D models; e.g., see Brooker, 2003). and rendered at a high resolution using texture and image post-processing (see Appendix B for parameters \& Appendix C for models). The male and female faces were cropped at the shoulders and arranged into separate matrices. The experiment was conducted online. Male and female faces were presented separately, and the order of presentation was counter-balanced across participants. Each face was presented with a label A-H and each matrix was accompanied by an 8-point attractiveness ranking scale. Participants were instructed to place the faces into a rank order from most attractive (1) to least attractive (8). Finally, participants were asked to report 
their age and sex. Model rankings were then analyzed in terms of three measures of central tendency: mean, median, and mode. These results are presented in Table 1. For the male models, male and female participants' rankings identified Spartacos and Beach Boy as the most attractive. Hence, they were selected for the main experiment. The female model rankings were less consistent, but Girl Next Door 4 and Marie were selected based on the rankings for all participants. For both the male and female participants, Girl Next Door 4 had the lowest mode, and the lowest (or second lowest) median. The other selected model, Marie, obtained the lowest (or second lowest) mean and median ranking from the male participants. She also obtained the lowest (or second lowest) median and modal ranking. Although she ranked fifth in mean rankings, only 02 separated her from the third place. Therefore, Girl Next Door 4 and Marie appeared to be reasonable choices. Henceforth, the four selected models will identified as Male 1, Male 2, Female 1, and Female 2, respectively.

Images were created from the four models selected in the pre-test. In order to generate the final appearance of the images, three pieces of software were used: Poser, Blender, and Photoshop. Images of the four original models represented the highest level of prototy picality. The remaining 6 levels of prototypicality were created by using Poser 7 to modify several anatomical features. Specifically, eye size, mouth height, and mouth size were increased in $12.5 \%$ increments to the maximum value allowed by the software; face height and eye separation were decreased in $12.5 \%$ decrements to the minimum allowable value (see Appendix D1 for the specific parameters and values used). These 28 models were then exported from Poser in the Wavefront .obj file format and imported into Blender 2.49. The Blender script "poly reducer" was used to reduce the number of polygons in the models in decrements of $43.5 \%$ (see Appendix D2 


\begin{tabular}{|c|c|c|c|c|c|c|c|}
\hline \multicolumn{4}{|c|}{ Malc Partuspants } & \multicolumn{4}{|c|}{1 emalc Purtucipants } \\
\hline Model & $(H(S D)$ & $M d n$ & lodk & Model & $M(S D)$ & Idn & Vode \\
\hline \multicolumn{8}{|c|}{ Male Model } \\
\hline Spartacos & $3+2(221)$ & 25 & 2 & Beach Bor & $389(176)$ & 3 & 3 \\
\hline Beach Bor & $403(214)$ & 3 & 3 & Spartacos & $433(249)$ & 5 & 1 \\
\hline Muchacho & $458(198)$ & 5 & 5 & Raphael & $446(252)$ & 5 & 8 \\
\hline Raphael & $462(232)$ & 4 & $t$ & Rob & $459(248)$ & 5 & 2 \\
\hline Sol & $460(226)$ & 5 & 7 & Muchacho & $463(218)$ & 4 & 4 \\
\hline Rob & $477(282)$ & 5 & 8 & Sol & $463(228)$ & 5 & 2 \\
\hline Lec & $485(207)$ & 5 & 4 & Michacl & $472(229)$ & 5 & 4 \\
\hline Michael & $504(236)$ & 6 & 6 & I ee & $474(228)$ & 55 & 7 \\
\hline \multicolumn{8}{|c|}{ I male Models } \\
\hline Mane & $369(185)$ & 4 & 4 & Lastern Grrl & $391(237)$ & 4 & 4 \\
\hline Victoria 42 & $389(199)$ & 3 & 3 & Gril Next Door 4 & $415(227)$ & 4 & 2 \\
\hline Gul Next Door 4 & $404(229)$ & 4 & 1 & Rio & $433(231)$ & 4 & 3 \\
\hline Stephane 4 & $435(297)$ & 45 & 1 & Ninv & $433(227)$ & 4 & 3 \\
\hline Asamı & $462(248)$ & 4 & 8 & Marıe & $435(241)$ & 4 & 3 \\
\hline Amy & $481(208)$ & 55 & 6 & Asami & $472(225)$ & 55 & 6 \\
\hline Lastem Girl & $527(215)$ & 6 & 6 & Victoria 42 & $483(191)$ & 5 & 5 \\
\hline Rio & $535(21)$ & 55 & 7 & Stephanie 4 & $537(234)$ & 6 & 8 \\
\hline \multicolumn{8}{|c|}{ All Participants } \\
\hline \multicolumn{4}{|c|}{ Male Models } & \multicolumn{4}{|c|}{ Female Models } \\
\hline Model & $M(S D)$ & $M d n$ & Mode & Modicl & $11(S D)$ & $M d n$ & Mode \\
\hline Girl Next Door 4 & $411(226)$ & 4 & 2 & Beach Boy & $394(188)$ & 3 & 3 \\
\hline Marıe & $414(225)$ & 4 & 3 & Spartacos & $404(243)$ & 4 & 1 \\
\hline Eastern Grrl & $435(238)$ & 4 & 4 & Raphael & $451(244)$ & 45 & 8 \\
\hline Amy & $449(221)$ & 4 & 7 & Muchacho & $461(211)$ & 45 & 4 \\
\hline Vactoraa 42 & $453(197)$ & 5 & 5 & Sol & $465(226)$ & 5 & 2 \\
\hline Rio & $466(278)$ & 4 & 3 & Rob & $465(258)$ & 5 & 8 \\
\hline Asam1 & $469(231)$ & 4 & 6 & Lee & $478(22)$ & 5 & 7 \\
\hline Stephanie 4 & $504(259)$ & 6 & 8 & Michdel & $483(23)$ & 5 & 7 \\
\hline
\end{tabular}

Note Models are listed in an ascending order by mean

Table 1 Measures of Central Tendency Obtaned for Pre-Test Models 
for poly reducer parameters, and see Appendix D3 for the resulting polygon counts for each model). One modification was necessary to Female 1's hair due to the technical challenge it posed for polygon reduction, and she was instead given Female 2's hair. The resulting models were then staged and rendered in Blender 2.56 using the same parameters as in the pre-test (see Appendix B). Finally, in order to increase the symmetry of the images, the two sides of each face were blended together at 50\% opacity using Photoshop. Images generated for Female 1 are presented in Figure 2. (see Appendices El-E3 for the stimuli produced for the other models). In all, 49 images were created for each model, corresponding to 7 levels of prototypicality and 7 levels of realism for a total of 196 stimuli. It was discovered after testing that Male 2 at Prototypicality level 4 had been mistakenly generated using parameters for Prototypicality level 3 , therefore Prototypicality level 3 has twice the number of observations, and level 4 is missing from the procedure and the results that follow.

Scales and measures. Subjective measures were obtained for human likeness, eeriness disgust, fear, and attractiveness using 7-point Likert scales. For each presentation, participants were asked to rate the extent to which they felt that the face shown on the computer screen was eerie, human-like, attractive, scary or disgusting depending on the trial. On each scale the endpoints and the mid-point were accompanied by labels ("Not at all", "Moderately", and "Extremely") to facilitate consistent interpretation of the scale and scale intervals across participants. See Appendix F1 for the scales used, and Appendix F2 for an example experimental trial.

\section{Procedure}

All testing, including stimulus presentation and the recording of participants' responses, 
was conducted using E-Prime 10 software (2002a, 2002b) Individuals were told that they

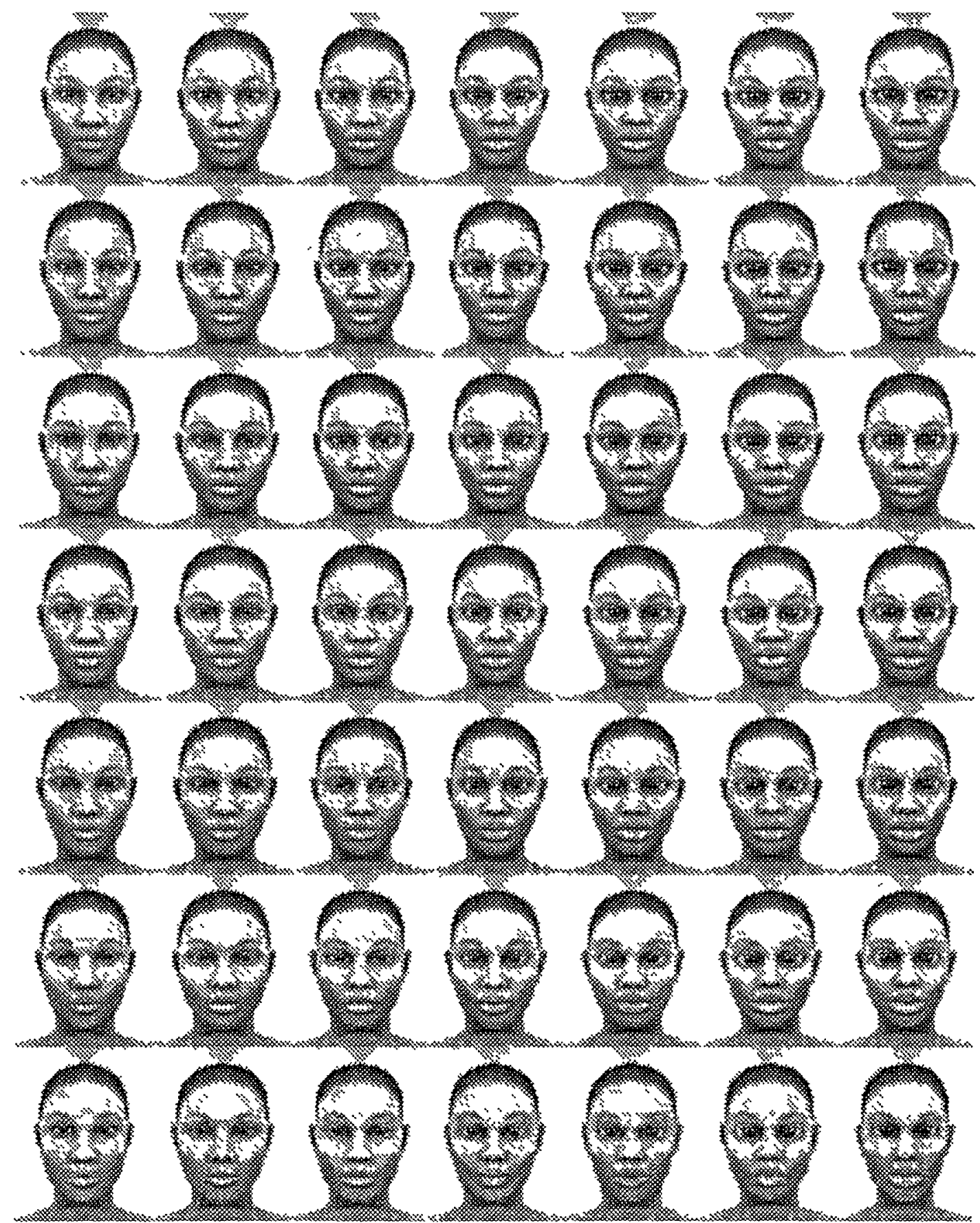

Figure 2 Stımulı Produced for Female 1 
would be reporting on their emotional reactions to computer-generated human faces. Due to time constraints and the potential for fatigue effects, participants were presented with one set of female and one set of male faces. Each set was presented in a separate block and the five subjective measures were presented with each face. The order of faces was randomized within each block to control for any possible order effects. The order of presentation of scales was also randomized for each face. Participants thus completed a total of 490 trials ( 2 sets of faces * 49 faces each * 5 scales for each face) in a single session lasting approximately 40-60 minutes. See Appendix F3 for experimental materials including informed consent and debriefing protocols.

\section{Results}

The data for one participant were lost due to a software malfunction and the data for another participant were removed because he failed to comply with the task instructions. Hence, the data for 162 participants ( 78 males, 84 females, $M_{\text {dge }}=20.4$, age range: $17-43$ years) were analysed.

\section{Evidence for the Uncanny Valley}

The uncanny valley's key prediction is that there should be a non-linear relationship between the human likeness of stimuli and the feelings of eeriness that they elicit. To obtain an initial overall impression concerning this relationship. human likeness and eeriness scores for all participants were first cross tabulated. The result is shown in the top left-hand portion of Figure 3. In this figure, each cell refers to the number of observations at the response categories for eeriness and human likeness, and cells are colour-coded based on frequency such that darker shades of grey represent more observations. It can be seen that the cells falling on the left to right diagonal contain the highest (or second highest) number of observations, suggesting a linear 
relationship betiveen the vanables To confirm this impression, mean ratıngs for each of the 189 stımulı were obtained by collapsing across individuals This procedure has been commonly used in the uncanny valley literature to examine this relatıonship (e g. MacDorman 2006, MacDorman \& Ishıguro. 2005. MacDorman et al 2009) Ratıngs were plotted separately for each base model ( $\mathrm{e}$. Male 1, Male 2, Female 1, and Female 2) These plots are presented in Figure 4

Humm Likeness

\begin{tabular}{|c|c|c|c|c|c|c|c|c|}
\hline & 1 & 2 & 3 & 4 & 5 & 6 & 7 & \\
\hline 7 & 81 & 298 & 149 & 93 & 42 & 28 & 27 & 1479 \\
\hline 6 & 6 & 617 & 349 & 261 & 152 & 69 & 32 & 2167 \\
\hline 5 & 493 & 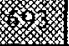 & 631 & 483 & 256 & 149 & 54 & 2759 \\
\hline 4 & 337 & $502 \pi$ & 543 & 533 & 405 & 230 & 89 & 2639 \\
\hline 3 & 189 & 347 & 415 & 558 & 366 & 233 & 94 & 2202 \\
\hline 2 & 167 & 240 & 328 & 483 & 505 & 417 & 246 & 2386 \\
\hline 1 & 105 & 72 & 80 & 144 & 225 & 367 & 6 & 1684 \\
\hline
\end{tabular}

Human Likeness

\begin{tabular}{|c|c|c|c|c|c|c|c|c|}
\hline & 1 & 2 & 3 & 4 & 5 & 6 & 7 & \\
\hline 7 & 639 & 143 & 66 & 43 & 20 & 10 & 12 & 933 \\
\hline 6 & 583 & 361 & 176 & 140 & 59 & 20 & 9 & 1348 \\
\hline 5 & 477 & 503 & 317 & 212 & 103 & 45 & 7 & 1664 \\
\hline 4 & 329 & 425 & 387 & 262 & 165 & 62 & 16 & $16+6$ \\
\hline 3 & 292 & 522 & 507 & 526 & 306 & 140 & 32 & 2325 \\
\hline 2 & 301 & 518 & 628 & 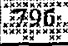 & 650 & 440 & 150 & 3483 \\
\hline I & 199 & 297 & 414 & 576 & 648 & 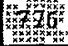 & y & 3917 \\
\hline
\end{tabular}

Human Likeness

\begin{tabular}{|c|c|c|c|c|c|c|c|c|}
\hline & 1 & 2 & 3 & 4 & 5 & 6 & 7 & \\
\hline 7 & 805 & 219 & 78 & 62 & 28 & 18 & 21 & 1231 \\
\hline 6 & 606 & 512 & 285 & 212 & 107 & 50 & 24 & 1887 \\
\hline 5 & 421 & 603 & 486 & 333 & 172 & 90 & 25 & 2130 \\
\hline 4 & 329 & 507 & 502 & 376 & 241 & 117 & 42 & 2114 \\
\hline 3 & 199 & 388 & 430 & $-536^{4}$ & 330 & 172 & 65 & 2120 \\
\hline 2 & 223 & 325 & 473 & 655 & 600 & $4 \frac{5}{46}$ & 157 & 2869 \\
\hline 1 & 146 & 215 & 241 & 381 & 473 & 610 & 繁 & 2965 \\
\hline
\end{tabular}

IIuman Likeness

\begin{tabular}{|c|c|c|c|c|c|c|c|c|}
\hline & 1 & 2 & 3 & 4 & 5 & 6 & 7 & \\
\hline 7 & 19 & 4 & 3 & 5 & 11 & 61 & 432 & 535 \\
\hline 6 & 15 & 16 & 16 & 39 & 122 & 341 & 335 & 884 \\
\hline 5 & 10 & 48 & 58 & 179 & 405 & 433 & 174 & 1307 \\
\hline & 26 & 100 & 256 & 546 & 501 & 228 & 102 & 1759 \\
\hline 3 & 95 & 312 & 576 & 639 & 345 & 157 & 75 & 2199 \\
\hline 2 & 390 & 1044 & 927 & 610 & 315 & 149 & 65 & 3500 \\
\hline & 6 & 1245 & 659 & 537 & 252 & 124 & 50 & 5132 \\
\hline
\end{tabular}

Figure 3 Shaded Crosstabs for Eeerıness, Fear, Disgust, and Attractiveness Ratıngs across Human Likeness Levels 
Figure 4 once again suggests linear relationships between eerıness and human likeness for each of the stımulus models These relatıonships were then tested by fitting linear $(y=a x+$ b). quadratıc $\left(y=a x^{2}+b x+c\right)$. and cubic $\left(y=a x^{3}+b x^{2}+c x+d\right)$ functions to the data This was performed with a regression analysis Specifically. the curve estımation procedure in $P A S W 18$ was used and eeriness was entered as the dependent varable and human likeness as the independent rariable If either a quadratic or cubic function were found to fit best, then either could reasonably be used as evidence to support the uncanny valley theory The results of these curve estımations are presented in Table 2

From these results, goodness-of-fit (GOF) can be assessed to determine which function best describes the data The first GOF statıstic that was computed is $R^{2}$. provided directly by the curve estımation procedure As Table 2 indicates, the magnitude of the linear trends was large for all stımulus models The magnitudes of the quadratıc and cubic trends were also large, but they were almost identıcal to the linear trends The second statıstic that was computed is the root mean squared error (RMSE, see Schunn \& Wallach, 2005) This was calculated by first using the GRG Nonlinear Solver function in Microsoft Excel 14 to generate a maximum likelihood estımation for the model, and then taking the square root of the residual error term The RMSE indicates the average squared difference between the estımate and the estımator, and is therefore given in standardized units Once more. the results for linear. quadratıc and cubic models were similar RMSE. however, is a siatistıc that is prone to over-estımate the fit of complex models. a phenomenon hnown as overfitting (Myung. 2000) This statıstic has the tendency to yleld better fits for functions with more parameters than those with fever parameters because the former can take advantage of the noise present in the data A GOF statıstıc that is commonly used to correct 
for overfitting is the Akaike Information Criterion (AIC; see Burnham \& Anderson, 2002). The AIC penalizes models with additional parameters (Myung. 2000). The AIC therefore has an advantage over the RMSE in that it is more likely to select a parsimonious model that will support valid inferences (Burnham \& Anderson, 2002). The AIC was calculated according to the general case formula, $A I C=-2 \log (L)+2 k$, where $L$ is the maximized likelihood estimation for the model and $k$ is the number of parameters (Bumham \& Anderson, 2002). As indicated in Table 2 , the linear function generated the lowest AIC value across the four stimulus models.

Additionally, the fits for the individual models were statistically significant at $p<.001$. Therefore, contrary to the prediction made by the uncanny valley theory, it may be concluded that human likeness and eeriness vary in a linear fashion. 


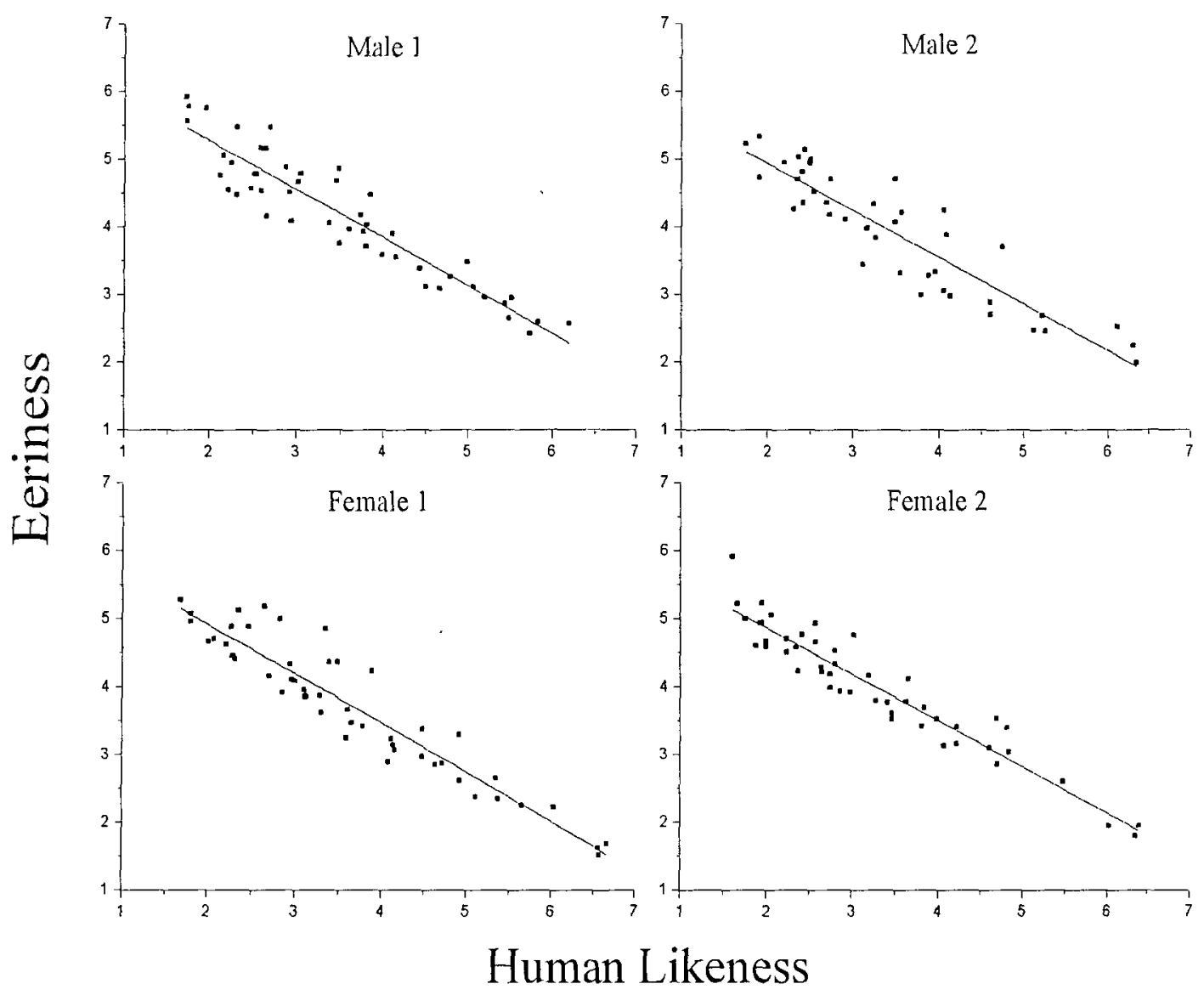

Figure 4. Mean Eeriness Ratings across Human Likeness, Aggregated by Stimulus and Separated by Stimulus Model. 


\begin{tabular}{|c|c|c|c|c|c|c|c|c|c|c|c|c|c|c|c|c|}
\hline & \multicolumn{4}{|c|}{ Male 1} & \multicolumn{4}{|c|}{ Male 2} & \multicolumn{4}{|c|}{ Fcmale 1} & \multicolumn{4}{|c|}{ Fcmale 2} \\
\hline & RMSE & $A I C$ & $R^{2}$ & $F$ & RMSE & $A I C$ & $R^{2}$ & $F$ & RMSE & $A I C$ & $R^{2}$ & $F$ & RMSE & $A I C$ & $R^{2}$ & $F$ \\
\hline \multicolumn{17}{|l|}{ Eeriness } \\
\hline Linear & 0.33 & 2.07 & .88 & 329.55 & 0.38 & 2.32 & .83 & 190.46 & 0.33 & 2.08 & .89 & 389.91 & 0.27 & 1.70 & .91 & 478.97 \\
\hline Quadratic & 0.33 & 4.05 & .88 & 2643.99 & 0.37 & 4.27 & .84 & 1511.94 & 0.33 & 4.07 & .89 & 2063.76 & 0.27 & 3.69 & .91 & 3683.65 \\
\hline Cubic & 0.32 & 6.05 & .88 & 1951.05 & 0.37 & 6.27 & .84 & 1104.88 & 0.33 & 6.07 & .89 & 1514.17 & 0.26 & 5.67 & .91 & 2766.71 \\
\hline \multicolumn{17}{|l|}{ Fear } \\
\hline Lincar & 0.37 & 2.26 & .87 & 326.21 & 0.42 & 2.48 & .80 & 164.36 & 0.34 & 2.10 & .91 & 454.43 & 0.34 & 2.15 & .90 & 442.73 \\
\hline Quadratic & 0.35 & 4.15 & .89 & 2029.03 & 0.37 & 4.27 & .85 & 1152.08 & 0.33 & 4.05 & .91 & 1781.88 & 0.32 & 4.02 & .92 & 1987.45 \\
\hline Cubic & 0.35 & 6.15 & .89 & 1489.49 & 0.37 & 6.27 & .85 & 842.74 & 0.31 & 5.98 & .92 & 1412.18 & 0.27 & 5.70 & .94 & 2126.88 \\
\hline \multicolumn{17}{|l|}{ Disgust } \\
\hline Linear & 0.33 & 2.05 & .89 & 378.08 & 0.32 & 2.01 & .85 & 228.06 & 0.25 & 1.57 & .93 & 613.87 & 0.24 & 1.52 & .94 & 687.42 \\
\hline Quadratic & 0.28 & 3.77 & .92 & 2254.18 & 0.31 & 3.94 & .86 & 1266.84 & 0.23 & 3.46 & .94 & 2835.38 & 0.22 & 3.40 & .95 & 3307.09 \\
\hline Cubic & 0.28 & 5.77 & .92 & 1658.67 & 0.28 & 5.81 & .88 & 1072.13 & 0.23 & 5.46 & .94 & 2080.30 & 0.21 & 5.25 & .95 & 2883.81 \\
\hline \multicolumn{17}{|l|}{ Attractiveness } \\
\hline Lincar & 0.13 & 0.48 & .98 & 1850.33 & 0.20 & 1.18 & .96 & 894.63 & 0.19 & 1.10 & .98 & 2109.74 & 0.18 & 1.03 & .98 & 2099.62 \\
\hline Quadratic & 0.13 & 2.42 & .98 & 6280.38 & 0.19 & 3.15 & .96 & 2653.41 & 0.12 & 2.34 & .99 & 10699.93 & 0.15 & 2.73 & .98 & 5990.21 \\
\hline Cubic & 0.13 & 4.39 & .98 & 4750.43 & 0.19 & 5.14 & .96 & 1970.90 & 0.12 & 4.33 & .99 & 7952.78 & 0.15 & 4.72 & .99 & 4426.57 \\
\hline
\end{tabular}

Note. All tests were significant at $p<.001$.

Table 2. Linear, Quadratic, and Cubic Curve Estimations for the Relationship between Eeriness, Fear, Disgust, Attractiveness with Human Likeness, Separated by Stimulus Model. 
Eeriness, however, may not be the only emotion for which a cubic function can be observed in relation to human likeness. The uncanny valley theory can be extended to predict that the basic relationship relating human likeness to eeriness holds for any emotion, including fear, disgust, and attractiveness. Therefore, these relationships were examined using the same approach taken with eeriness. First, individual ratings for each of the emotions were plotted against ratings for human likeness. These plots are presented in Figure 3. An examination of this fjgure suggests that human likeness is also linearly related to fear, disgust, and attractiveness. Therefore, ratings were collapsed across participants to obtain ratings for each of the stimuli. Mean emotional ratings for each stimulus were then plotted across mean human likeness. These plots are presented in Figures 5, 6 and 7. 


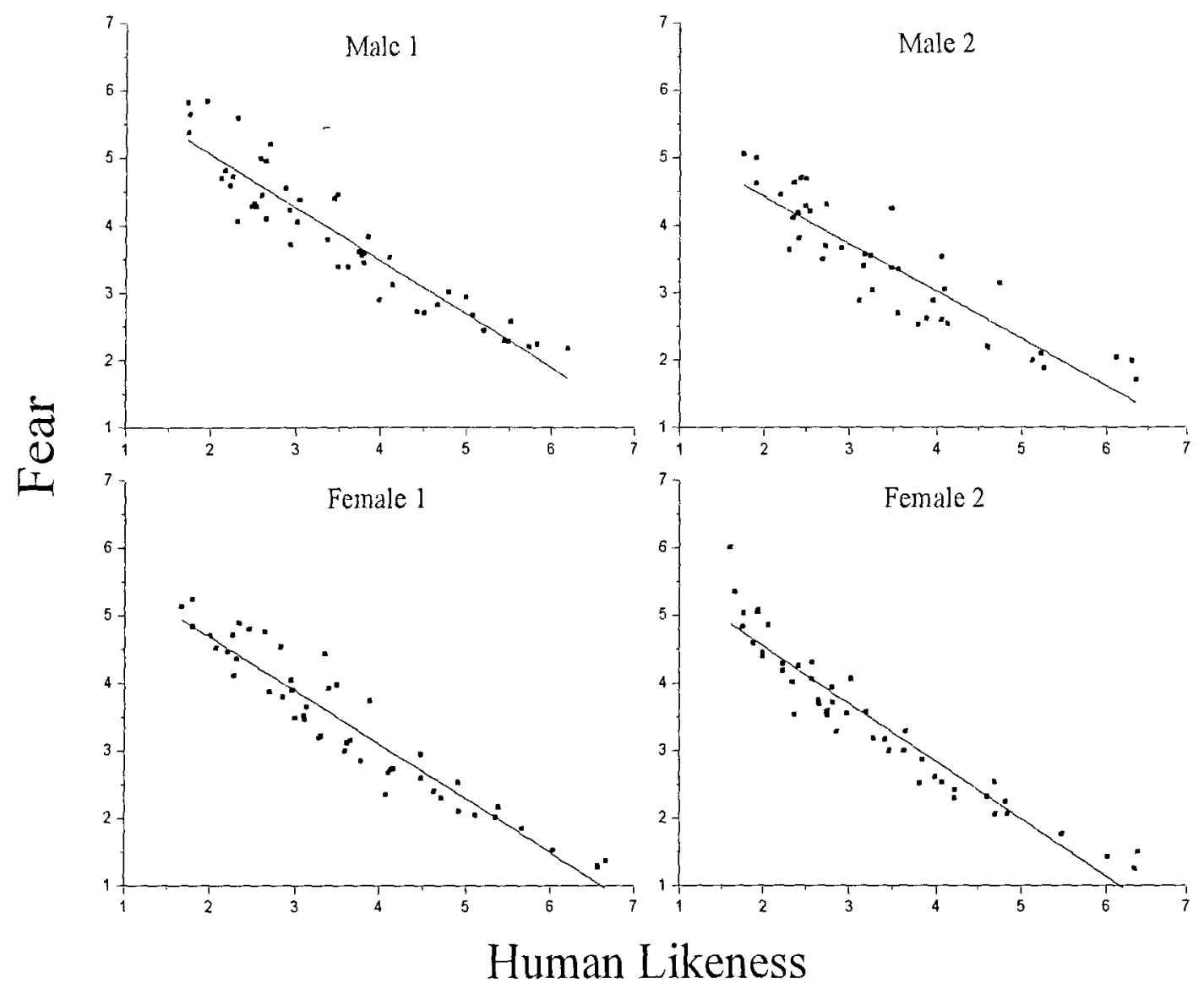

Figure 5. Mean Fear Ratings across Human Likeness, Aggregated by Stimulus and Separated by Stimulus Model 


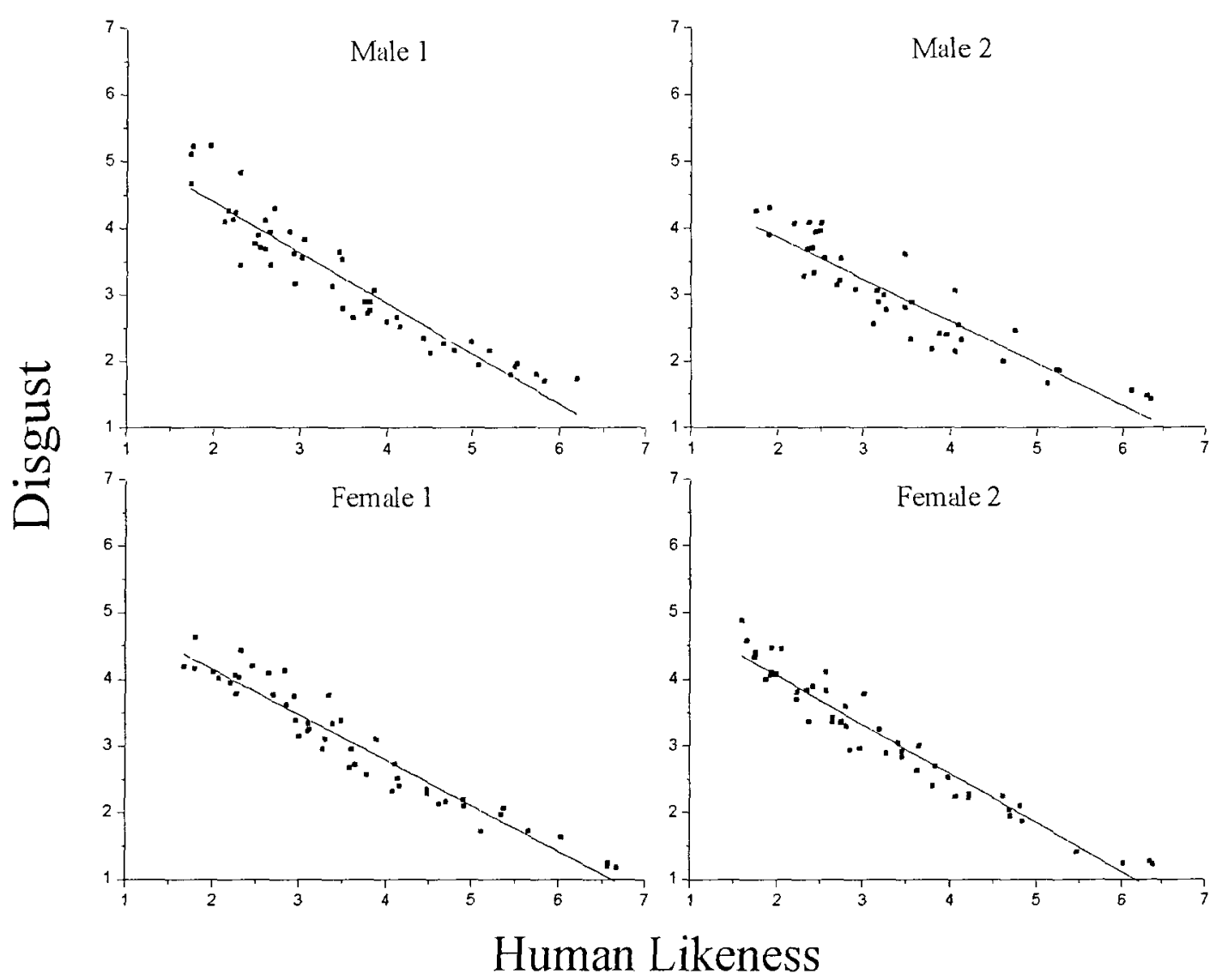

Figure 6. Mean Disgust Ratings across Human Likeness, Aggregated by Stimulus and Separated by Stimulus Model. 


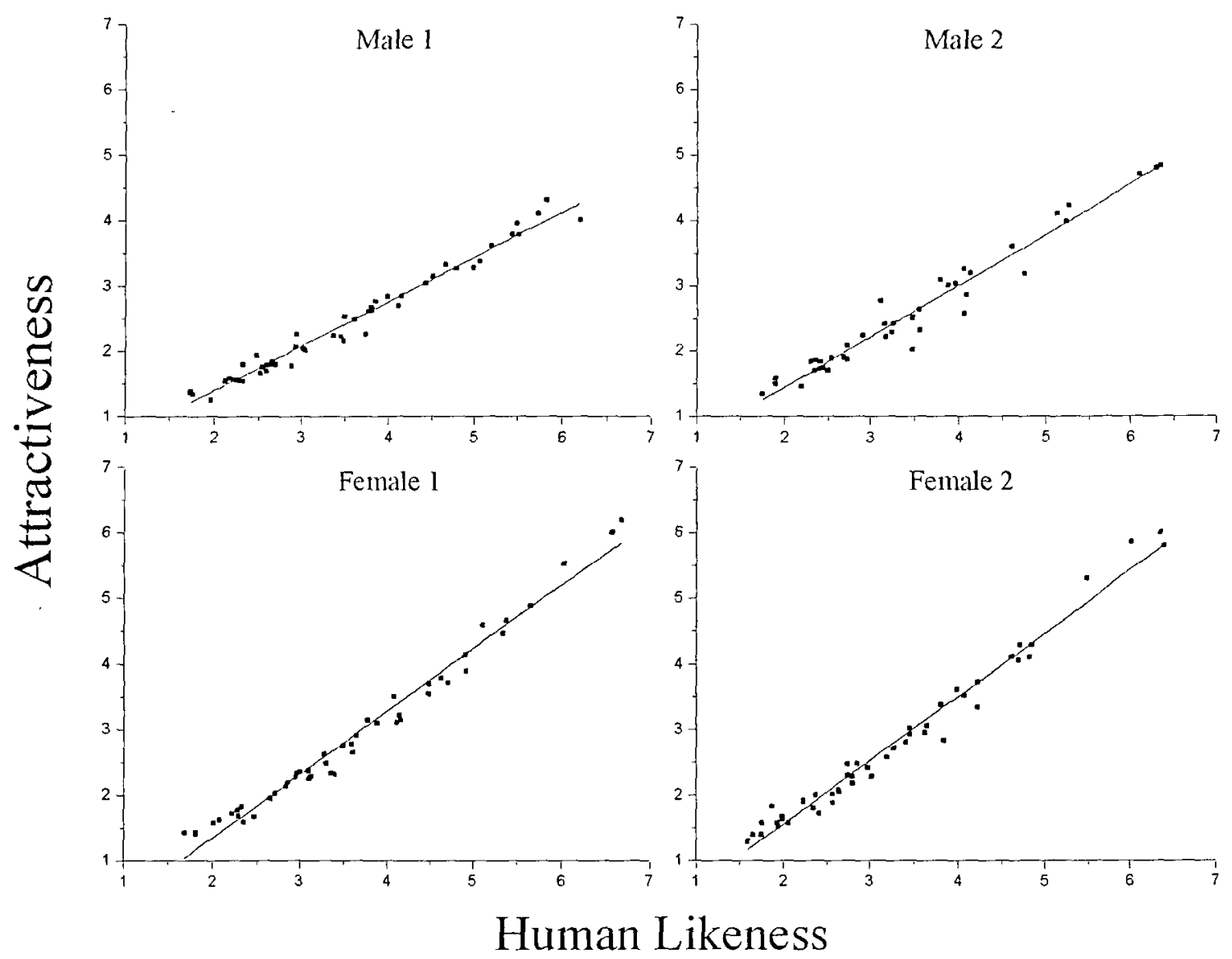

Figure 7. Mean Attractiveness Ratings across Human Likeness, Aggregated by Stimulus and Separated by Stimulus Model.

Once more, Figures 5, 6 and 7 seem to indicate that linear relationships describe the relation between human likeness and fear, disgust, and attractiveness respectively, for each of the four stimulus models. To confirm these impressions, the fit of linear, quadratic, and cubic functions to these relationships were examined. These results are presented in Table 2. 
According 10 Table 2, the magnitude of a linear trend was large for each of the emotions and for each of the stimulus models. The magnitude of the quadratic and cubic functions was also large and these functions explained up to $5 \%$ additional variance. These models were corrected for overfitting using the AIC to facilitate identifying the most parsimonious model. According to the AIC, the best fitting function across each of the stimulus models and subjective responses was linear. Additionally, all models were statistically significant at $p<.001$. It may therefore be concluded that the relationships between emotional responses that were measured and human likeness were linear. This conclusion is further evidence against the uncanny valley theory.

A limitation cited in previous research has been that not enough stimulus models were used (e g., MacDorman et al , 2009). This is a concern because if stimuli are generated from a single base model, then observations may be driven by particular features which are unique to that model. The present experiment generated stimuli from four base models. Although these models were pre-selected based on attractiveness to be average, and therefore representative of human-like objects, the possibility still exists that findings could be driven by stimulus particularities. Before the relationships between human likeness and subjective responses can be assumed to be of a general nature, it must be shown that there are no systematic differences between the stimulus models. To preclude this possibility, pairwise comparisons were generated to examine differences between mean ratings of the four stimulus models on each of the subjective rating scales. A t-test was calculated for each comparison and corrected using a Bonferroni adjustment for 30 tests $(.05 / 30=.002)$. Comparisons are presented in Table 3. 


\begin{tabular}{|c|c|c|c|c|c|c|}
\hline & \multicolumn{2}{|c|}{ Malc 1} & \multicolumn{2}{|c|}{ Malc 2} & \multicolumn{2}{|c|}{ Fcmale 1} \\
\hline & $t$ & $p$ & $t$ & $P$ & $t$ & $p$ \\
\hline \multicolumn{7}{|l|}{ Male 2} \\
\hline Human Likeness & 0.19 & .85 & & & & \\
\hline Attractiveness & 0.55 & .59 & & & & \\
\hline Ecrincss & 0.92 & .36 & & & & \\
\hline Fcar & 1.49 & .14 & & & & \\
\hline Disgust & 1.04 & .30 & & & & \\
\hline \multicolumn{7}{|l|}{ Female 1} \\
\hline Human Likcncss & 0.68 & .50 & 0.94 & .35 & & \\
\hline Attractiveness & 2.49 & .01 & 1.80 & .07 & & \\
\hline Eeriness & 2.24 & .03 & 1.01 & .31 & & \\
\hline Fear & 2.28 & .02 & 0.24 & .81 & & \\
\hline Disgust & 1.01 & .32 & 0.40 & .69 & & \\
\hline \multicolumn{7}{|l|}{ Female 2} \\
\hline Human Likeness & 1.36 & .18 & 0.23 & .28 & 0.44 & .04 \\
\hline Attractiveness & 1.54 & .12 & 0.17 & .40 & 0.21 & .33 \\
\hline Eeriness & 0.79 & .43 & 0.10 & .64 & 0.32 & .14 \\
\hline Fear & 1.68 & .10 & 0.09 & .69 & 0.14 & .53 \\
\hline Disgust & 0.70 & .49 & 0.16 & .46 & 0.07 & .75 \\
\hline
\end{tabular}

Table 3. Pairwise Comparisons of Subjective Ratings between Each Model.

As Table 3 indicates, none of the comparisons were significant. The smallest $p$-value obtained when comparing the attractiveness of Male $1(M=2.44, S D=1.88)$ with Female $1(M=$ $2.96, S D=1.86$ ) was $p=.01$. This comparison also produced the largest mean difference of .52 (Cohen's $d=.28$ ). Thus, these results suggest that although there might have been small differences between the models for some of the scales, there were no systematic differences that could lead to concerns about stimulus specific confounds.

While the uncanny valley phenomenon is generally thought to be connected to subjective human likeness, some studies have produced evidence in its support by relating emotional response to objective levels of human likeness (e.g., Seyama \& Nagayama, 2007). Although it has been established in the present experiment that a linear relationship exists between emotional 
response and subjective human likeness, it is still possible that the relationship between emotional response and objective human likeness, as determined by levels of the stimulus parameters, might evidence the uncanny valley. Therefore, this possibility was examined this by collapsing ratings across the stimulus models, and then plotting mean emotional responses across prototypicality and realism levels. These plots are presented in Figure 8.
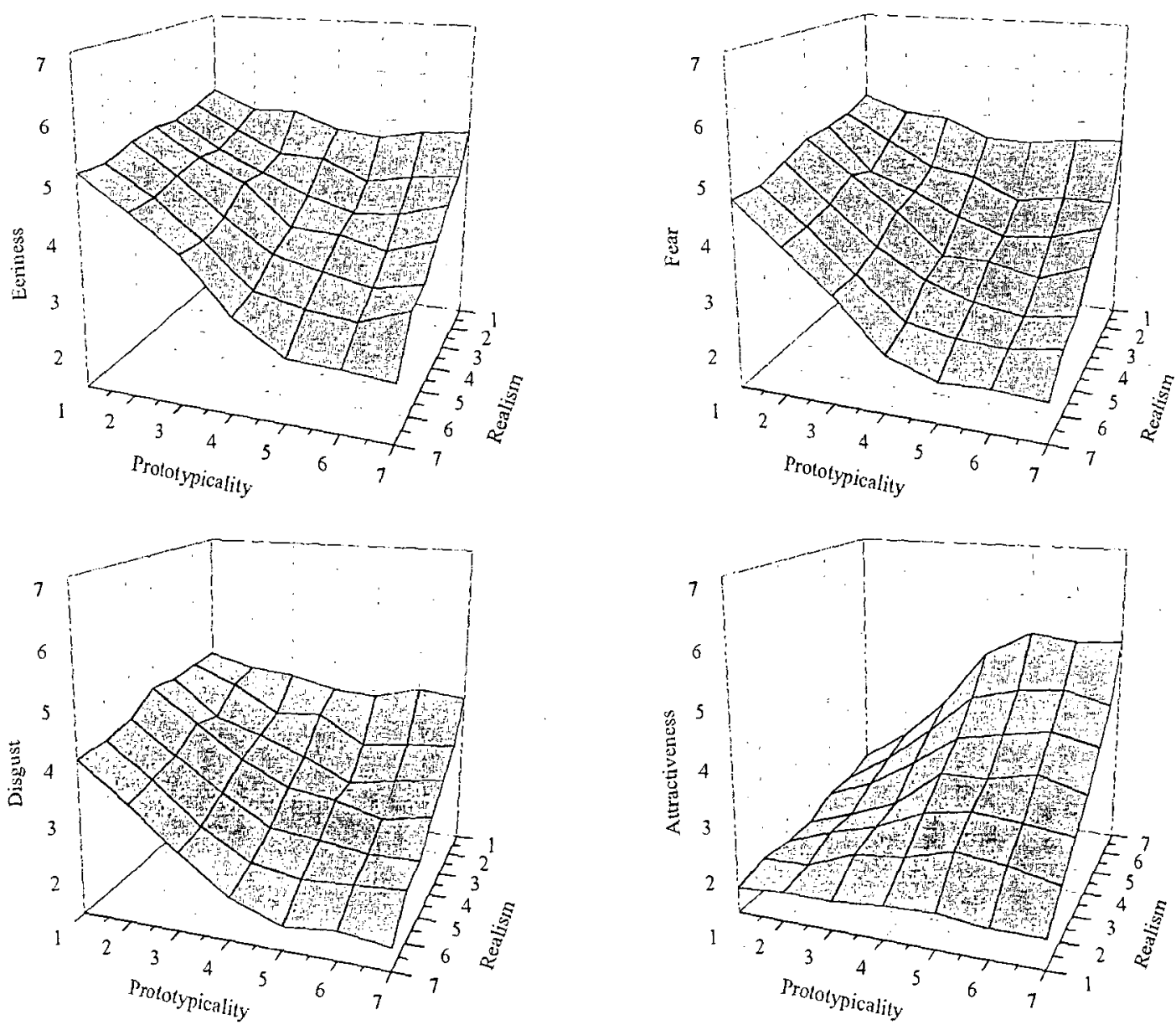


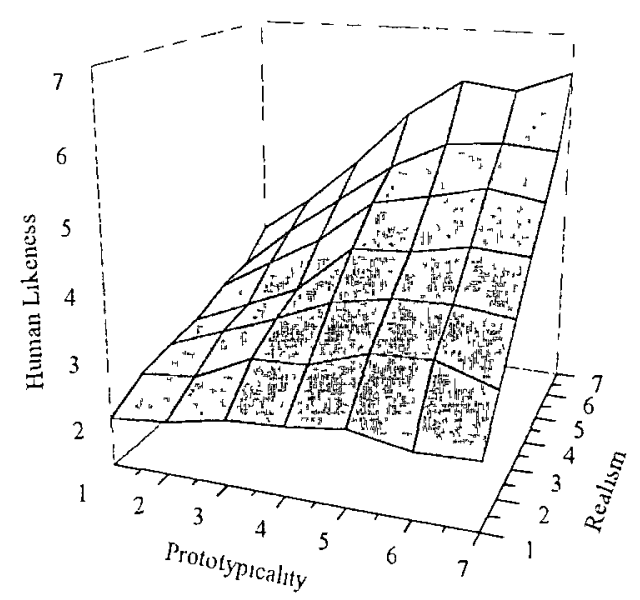

Note The direction of the realism scale has been reversed for Human Likeness and Attractiveness

Figure 8. Surface Plots for Mean Eeriness, Fear, Disgust. Attractiveness, and Human Likeness Ratıngs across Prototypicality and Realism Levels.

According to the uncanny valley, when human likeness is related to eeriness, the resulting function should be cubic. When eeriness is related simultaneously to two stimulus parameters that may have an impact on human likeness, however, many different distributions could be found to support the uncanny valley. For instance, given a linear relationship with one variable and a cubic relationship with the other, the distribution of data points might resemble Figure 1 but on a plane rather than a line. Given two cubic relationships, the distribution of data might resemble a distorted bivariate normal distribution with one side of the distribution "higher" than the other. Regardless of the particular shape that might be expected of an uncanny valley in three dimensions, the distribution of data would be expected to deviate from bivariate linearity. However, the plots in Figure 8 suggest that this was not the case. Instead, it suggests that bivariate linear relationships exist between the stimulus dimensions (i.e, prototypicality and realism) and subjective ratings. With the negative rating scales (eeriness, fear, and disgust), the 
plane is sloped down and it converges at the highest levels of prototypicality and realism where ratings are the lowest With positive ratings (human likeness and attractiveness), the plane is sloped upward and it converges at the highest levels of prototy picality and realism where ratings are the highest. A bivariate linear function was therefore fit to these data using the GLM procedure in SPSS 17, entering eeriness as a dependent variable and prototypicality and realism as independent variables. These results are presented in Table 4.

\begin{tabular}{lccc}
\hline Emotions & $R^{2}$ & $R M S E$ & $F$ \\
\hline Eeriness & 0.72 & 0.26 & 158.27 \\
Fear & 0.73 & 0.31 & 169.61 \\
Disgust & 0.78 & 0.19 & 215.67 \\
Attractiveness & 0.74 & 0.32 & 174.72 \\
Human Likeness & 0.84 & 0.26 & 314.70 \\
\hline \multicolumn{4}{l}{ Note. All tests reached significance, $p<.001$}
\end{tabular}

Table 4. Bivariate Linear Fits for the Relationships between Eeriness, Fear, Disgust, Attractiveness, Human Likeness with Prototypicality and Realism.

For all models, a strong relationship between the stimulus dimension (prototypicality and realism) and emotions was found. They explained at least $72 \%$ of the variance. Therefore, these fits suggest that bivariate linear functions provide more than adequate fits to the data sets. While it would undoubtedly be possible to fit more complex functions to the data, an examination of the surface plots presented in Figure 8 make it highly unlikely that any function fit would provide support for the uncanny valley.

\section{The Relationships between Eeriness and Other Emotions}

A theoretical examination of eeriness has identified several emotions with which it should display strong relationships. These emotions include fear, disgust and attractiveness. Ho et al. 
(2008) found this to be the case, and more specifically, they found that eeriness was related most closely to fear, followed by disgust and attractiveness. Similar results were expected from the present experiment. The relationships between emotions were first examined by calculating pairwise bivariate correlations. A correlation matrix is presented in Table 5. --

\begin{tabular}{|c|c|c|c|c|}
\hline & Eerie & Fear & Disgust & Attractiveness \\
\hline Fear & .71 & & & \\
\hline Disgust & .61 & .72 & & \\
\hline Attractiveness & -.51 & -.51 & -.50 & \\
\hline & \multicolumn{4}{|c|}{$M(S D)$} \\
\hline & $3.96(1.83)$ & $3.52(1.94)$ & $3.09(188)$ & $2.69(1.73)$ \\
\hline
\end{tabular}

Note. All corrclations werc significant at $p<.01$.

Table 5. Bivariate Correlation Matrix between Emotions.

As predicted, Table 5 indicates that eeriness was most strongly correlated with fear, followed by disgust and attractiveness. Although these correlations are in line with expectations, Ho et al. (2008) had previously examined these relationships in terms of variance explained in eeriness by other emotions. Thus, the relationships were next examined by conducting a forward stepwise regression analysis with eeriness as the criterion, and fear, disgust, and attractiveness as predictors. These results are presented in Table 6. Because fear produced the largest significant linear term $(\beta=.71, t=124.902, p<.001)$, it was entered first into the model, and was observed to explain $50.5 \%$ of the variance in eeriness $\left(R^{2}=.505 ; A d j . R^{2}=.505\right)$. With fear in the model, the next predictor with the largest significant linear term was attractiveness $(\beta=-.208, t=$ $32.498, p<.001)$, which explained an additional $3.2 \%$ variance $\left(A R^{2}=.032\right)$. With fear and attractiveness in the model, the final predictor entered into the model was disgust $(\beta=.165, t=$ 20.787, $p<.001)$, which explained an additional $1.3 \%$ variance $\left(\Delta R^{2}=.013\right)$. Therefore, based 


\begin{tabular}{llll}
\hline & $R^{2}$ & $\Delta R^{2}$ & $B$ \\
\hline Step 1 & .505 & .505 & \\
$\quad$ Fear & & & .710 \\
Step 2 & .537 & .032 &. \\
$\quad$ Fear & & & .604 \\
Attractive & & & -.208 \\
Step 3 & .549 & .013 & \\
Fear & & & .500 \\
Attractive & & & -.179 \\
Disgust & & & .165 \\
\hline
\end{tabular}

Note. All tests were significant at $p<.001$.

Table 6. Stepwise Regression Analysis Predicting Eeriness from Fear, Disgust, and Attractiveness.

on the emotions measured in the present experiment, it appears that eeriness is predominantly related to fear.

\section{Discussion}

The present thesis had two main goals. The first goal was to test the validity of the uncanny valley theory (MacDorman et al., 2009; MacDorman \& Ishiguro, 2006; Mori, 1970). It predicts that people's emotional response toward stimuli will vary as a function of human likeness. More specifically, the uncanny valley's key prediction is that stimuli with a high degree of human likeness will be perceived as much eerier than stimuli that have either a low or a perfect degree of human likeness. Although a number of studies have examined the theory empirically (Bartneck et al., 2007; MacDorman, 2006; MacDorman et al., 2009; MacDorman \& Ishiguro, 2006; Schneider et al., 2007; Seyama \& Nagayama, 2007; Steckenfinger \& Ghazanfar, 2009), the findings have been inconsistent. Furthermore, the different methodologies that have been used, especially with regards to stimulus creation, have led to results that are open to interpretation. The greatest concern pertained to stimuli that confounded degrees of human 
likeness and the inclusion of atypical or non-human features (e.g., MacDorman \& Ishiguro, 2006; Seyama \& Nagayama, 2007). In the present experiment, these methodological issues were addressed by manipulating two parameters: prototypicality and geometric realism. These choices ensured that the stimuli would vary sufficiently in their human likeness to find the uncanny valley, if it exists, without any other factors being present to influence the outcome.

The second goal of this thesis was to explore the nature of eeriness. Eeriness has been identified as an emotional response to uncanny stimuli. Several competing theories of eeriness have been proposed (MacDorman et al., 2009; MacDorman \& Ishiguro, 2006), but so far only one study has been carried out to examine them (Ho et al., 2008). According to these theories eeriness may emerge as a by-product of other cognitive processes, such as those involved in monitoring for potential mates, signs of disease, physical threats, or those involved in terror management. This experiment was designed to test these theories by examining the relationship between eeriness and three key emotions relating to these processes: attractiveness, disgust, and fear.

\section{The Uncanny Valley}

The primary finding of the present experiment is that the relationships between the emotional responses and human likeness were strongly linear. This was observed for all four of the emotions tested: eeriness, fear, disgust, and attractiveness. Therefore, there was no evidence to support Mori's (1970) uncanny valley theory. A potential concern that could be raised about these results is that a restricted range in the human likeness of the stimuli failed to capture the full cubic function predicted by the uncanny valley theory. An examination of Figure 1 indicates that two segments of the uncanny valley function are linear (between $0-60 \%$ and $80-100 \%$ 
human likeness). Therefore, if stimuli had elicited subjective human likeness ratings within either of these ranges, then the resulting function with any given emotion $w$ ould have been linear. However, this argument does not appear to be plausible because the results indicated that participants made use of the full range of the human likeness and emotion scales. Furthermore, it may be added that the present methodology was an extension of MacDorman et al.'s (2009) study. Nevertheless, this methodology was improved by using four models instead of one and by using models with greater realism. Moreover, models were designed by commercial artists and then modified and rendered using professional software. In this way, the appearance of stimuli approximated the level of realism found in modern films and interactive media. The present experiment thus appears to be the most comprehensive test of the uncanny valley theory to date.

A closer examination of the operationalization of human likeness may help to reconcile present findings with extant studies found in the literature. The linear relationship observed between human likeness and emotional response runs counter to MacDorman and Ishiguro (2006), who found that negative emotions peak at intermediary levels of subjective human likeness, but is consistent with MacDorman et al. (2009), who also observed a positive linear relationship between human likeness and emotional response. The reason for these differences appears to be due to the manner in which stimuli were created. In the present experiment, stimuli were created, like MacDorman et al.'s (2009), by modifying two specific features related to human likeness. In contrast, MacDorman and Ishiguro (2006) created stimuli by morphing images of a robot with images of a human. By morphing these images together, stimuli were generated which had both human and non-human features. Using this morphing process, human likeness has also been operationalized as the location of a stimulus in the morphing sequence. 
Operationalized in this manner, Seyama and Nagayama (2007) observed a non-linear relationship between human likeness and emotional response. Once again, because human and non-human images were morphed together, this procedure produced stimuli with features unrelated to human likeness. In another relaied`study, Mitchell, Szerszen, Lu, Schermerhom, Scheutz, and MacDorman's (2011) examined how a face-voice mismatch betiveen human and robot stimuli affected emotional response. Human characters were presented speaking with a human or robot voice, and robot characters were presented speaking with a robot or human voice. They observed that a robot with a human voice was rated as more human-like than a robot with a robot voice, but it was also rated as more eerie. Moreover, a human with a robot voice was rated as more human-like than a robot with a human voice, and it was also rated as more eerie. $\mathrm{A}$ pattern which emerges from these three studies is that human-like stimuli which possess inhuman features are eerie. It may be supposed that because these stimuli have features belonging to two ontologically separate categories, they are perceived simultaneously as belonging to two categories of object (e.g., human and robot). The negative emotional response which is found with these stimuli might be a direct consequence of this categorical conflict. Consider the phenomenon known as cognitive dissonance. It states that when an individual holds two contradictory ideas simultaneously they experience an uncomfortable feeling which motivates them to resolve the conflict (Elliot \& Devine, 1994). Stimuli which are perceived as both human and non-human similarly present a contradiction. It is therefore possible that the data obtained from these studies can be explained by understanding eeriness as a phenomenon similar to cognitive dissonance. 
Saygin, Chaminade, Ishiguro, Driver, and Frith's (2011) recent neuroimaging research may be presented in support of this claim. The authors hypothesized that an agent s appearance would activate a single neural model in an observer that makes predictions regarding the agent's behaviour. For example, an agent with a-human-like appearance will activate a human neural model and an agent with a robot-like appearance will activate a robot neural model. Because androids have a human-like appearance, but robot-like movement, Saygin et al. hypothesized that the eeriness which has previously been associated with androids might be due to prediction error arising from the activation of the vvrong neural model. To test this hypothesis, they presented videos to their participants depicting a human actor, an android modeled from the human actor, and a robot. Each video showed simple actions like picking up a cup. Individuals were presented with each video once and were told whether it was a human actor or a robot. In the case of androids, participants were told that these agents were robots. Then, individuals were presented with the videos a second time while undergoing an AMRI. When the android videos were presented, the activity observed in the temporal and parietal cortices was different than that seen when the human or robot videos were presented. Saygin et al. concluded that the additional brain activity observed during the presentation of androids was due to their human-like appearance which activated error-prone human neural models. In other words, the brain activity is assumed to reflect a disparity between the biological movement predicted by a human neural model and the actual machine-like movement of the agent. The function of these neural models must be generalized if this explanation is to account for the data obtained by MacDorman and Ishiguro (2006) and Seyama and Nagayama (2007) who used static stimuli. However, Saygin et al.'s findings may also be interpreted in line with the conflict hypothesis, which would involve a 
different cognitive mechanism altogether. If it is assumed that android stimuli, which possess human-like appearance and robot-like movement, simultaneously activate a human neural model and a robot neural model, then the additional brain activity observed might be taken to reflect processes involved in the resolution-of this conflict. In summary, it appears that extant literature which has observed the uncanny valley phenomenon may be interpreted in one of two way's: as the violation of normative expectations or as the simultaneous activation of two stimulus interpretations which are in conflict:

\section{Eeriness}

The present experiment measured emotional reactions pertaining to eeriness, fear. disgust, and attractiveness. These emotions were selected as they may be viewed as the activation of cognitive processes which have been associated with eeriness. Fear may be associated with threat avoidance or terror management, disgust with disease avoidance, and attractiveness with mate selection (Amdt et al., 1997; Rhodes, 2006; Thorrthill \& Gangestead, 1993). Present results observed a strong relationship between fear and eeriness. Therefore, it may be supposed that eeriness is related to threat avoidance or terror management. Disgust and attractiveness provided relatively weak contributions to an explanation of eeriness. Thus, the involvement of disease avoidance and mate selection processes appear to be modest at best. Consistent with the present findings, Ho et al. (2008) had observed that, among 27 different emotions, fear generated the strongest relationship with eeriness. However, they had also observed much stronger relationships between eeriness and disgust and eeriness and attractiveness. The reason for these differences may be due to the stimuli that were used or participants' past experience with similar stimuli. While Ho et al. (2008) had used robots, 
computer generated images were used in the present experiment. The eerie robot stimuli possessed features which were not found on eerie digital humans. Ho et al. (2008) also mentioned that participants had little or no prior exposure to robots, but it is likely that participants in the present experiment which were recruited from a North American university had at least moderate exposure to digital humans. There may also have been cultural and language differences. The present experiment was conducted in English using a population sampled from a North American culture. In contrast, Ho et al. (2008) had tested individuals using scales translated from English into Bahasa Indonesia using a population sampled from Indonesia. Although steps were taken to minimize language differences, the Indonesian terms used to denote eeriness and the other emotions may still have had different cultural connotations than their English counterparts. Nevertheless, in both cases eeriness was found to be predominantly related to fear.

In the context of the uncanny valley, fear has one of two possible meanings. When Mori (1970) outlined the uncanny valley theory, he suggested that uncanny stimuli were eerie because they looked like human corpses: pale, stiff, and vacant. MacDorman (2005) aligned this notion with Terror Management Theory (Arndt et al., 1997), which proposes that even subtle cues indicative of death can elicit uncomfortable feelings of apprehension because they serve as a reminder of mortality. When MacDorman (2005) presented an eerie android to individuals, he observed an expected increase in the frequency of death-related cognitions. Alternatively, the atypical features which are found on eerie stimuli might be scary because they are unusual or because they connote internal mental states which are suspect. Although fear generated a strong 
relationship with eeriness in the present experiment, the measurements obtained were not designed to make a determination as to the specific nature of this fear.

One key characteristic that differentiates threat avoidance from terror management processes is physiological response. Common symptoms associated with a visceral fear response include an increased heart rate, sweating, dilation of the pupils, and a tightening of the chest. Thus, a visceral fear is manifested in the sympathetic nervous system. In contrast, the fear of death has not been observed to cause any somatic changes (Greenberg et al., 1994). The nature of fear which is associated with eeriness could be specified if measurements of subjective eeriness were obtained, in addition to physiological response (e.g., galvanic skin response) and the frequency of death thoughts (e.g., with fill-in-the-blanks).

\section{Conclusions and Future Directions}

This research suggests that the uncanny valley theory is incorrect in assuming that ratings of eeriness vary as a cubic function of stimulus human likeness. Therefore, the uncanny valley theory is not a valid explanation for why certain human-like objects are eerie. Nevertheless, certain operationalizations of human likeness have been observed to produce a relationship between emotional response and human likeness which resembles Figure 1, such as those which have morphed humans with non-humans. One may argue that the reason for these differences lies in the endpoints of the stimulus dimension of human likeness, such that an uncanny valley function is produced only when maximal human likeness is portrayed by a real human or minimal human likeness by a non-human. This appears unlikely to be the case considering the location of the uncanny valley obtained in previous experiments which used such endpoints (e.g., MacDorman \& Ishiguro, 2006) was not located near either of the two extremes. Instead, these 
differing results may be accounted for by one of two hypotheses. According to one hypothesis, stimuli which possess both human and non-human features should be eerie due to cognitive dissonance. According to the second hypothesis, stimuli which appear to be human but possess atypical features should be eerie due to a violation of expectations.

These hypotheses could be investigated by extending the methodological procedure used in the present study (See also MacDorman et al., 2009). Two sets of digitally-produced faces could be first created: one that produces a continuum of human likeness similar to the one used in the present experiment and another that merges two distinct models (e.g., a human and an animal) into a continuum similar to the one used in MacDorman and Ishiguro's experiment (2006). Then, for both sets of stimuli, a given feature (e.g., the eye) could be gradually distorted and exaggerated to incrementally transform it into a highly atypical feature. The resulting twodimensional sets could then be submitted to participants' judgments of human likeness and eeriness. In this way, human likeness would be created both within a single ontological category and between two ontological categories. The effect of feature atypicality across both operationalizations of human likeness could also be examined. If a violation of normative expectations is responsible for eeriness, then it would be expected that higher levels of feature atypicality would be eerier at higher levels of human likeness. If a categorical conflict is responsible for eeriness, then the location on the continuum which lies mid-way between human and animal would be maximally eerie because it would activate two neural models with equal strength.

Ongoing research on the uncanny valley is important for designers who wish to avoid the conditions that cause human-like characters to become eerie. Present data suggests that human 
likeness is negatively correlated with eeriness. Hence, designers would be advised to continue their pursuit of still greater forms of human likeness and realism without apprehension Nevertheless, the causes of eeriness are not yet well understood, and the relationship betw een human likeness and eeriness may be mediated by different factors, such as the resemblance of a stimulus to ontological categories other than human or the presence of aty pical features. If the uncanny valley phenomenon is caused by human-like characters that possess features from other ontotogical categories, then designers would be advised, for example, to minimize the animal- or machine-likeness of design. This may involve increasing the fluidity of movement by increasing the resolution of motion capture, or making use of the principles of evolutionary aesthetics such as averageness, symmetry, and sexual dimorphism. If the uncanny valley phenomenon is caused by a violation of normatuve expectations, however, then greater levels of human likeness would be preferable, due to an increase in realism and immersion, but also riskier, due to potentially stronger violations. Under these circumstances, designers would have two options. They may attempt to minimize risk or maximize reward. Minimizing risk would be the approach that Mori (1970) called "escape by design," which involves designing human-likenesses with visibly artificial elements and placing an emphasis on aesthetics rather than realism, such as using cartoon-like humans (Hanson, 2005). For example, in the movie Avatar (Laundau \& Cameron, 2009), realistic animated characters were produced that were human-like in terms of anatomy and movement, but also much taller than humans with blue skin and exaggerated facial features. In contrast, maximizing reward places an emphasis on realism. According to present results, the realism of human characters can be increased without increasing eeriness. Digital models used for this study were selected for evolutionary aesthetics such as averageness and symmetry. 
Therefore, evolutionary aesthetics may be an important consideration for designers under this hypothesis as well.

Researchers have begun to identify other design elements which can cause human-like stimuli to become eerie, such as mismatched realism (Mitchell et al., 2011) and the lack of upper face animation when expressing emotion (Tinwell et al., 2011). Future research may continue to identify these properties in order to make more specific recommendations and designers may be - able to manage risk with an awareness of these aspects of design. In its movement towards perfect human likeness, technology will challenge our ability to discriminate between what is real and what is not. Yet, before this final goal can be realized, there is still much to be discovered regarding the correspondence between conveying human appearance to artificial forms and the elicited subjective experience. 
Appendı A

Maten lals List for Pre-Test

\begin{tabular}{|c|c|}
\hline Basc Models & Location (URL) \\
\hline Vicloria 42 & http $/ /$ u w \\
\hline Michael 4 & http //uwn da7 3d com 1/3d-models - michacl-4-base $1 t$ enı-7877\&_m-d \\
\hline Stephame 4 & 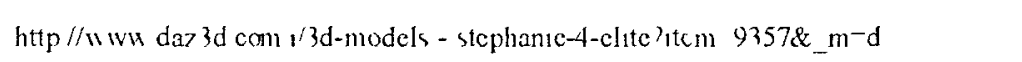 \\
\hline Base Derivaliues & Location (URL) \\
\hline Amy for $\mathrm{V} 4$ & http $/ /$ w wu daz $3 \mathrm{~d} \mathrm{com}$ 1/shop/1temdetals ' 'tem-7377 \\
\hline Asam for $\mathrm{V} 4$ & http /'u wи renderosity com mod bes'index php'Vicu Product 82431 \\
\hline Beach Boy for M4 & http / ww renderosity com/nod bes beach-bos-add-on 80101 \\
\hline Eastern Gırl for V4 & http / шин renderosity com/mod bes indes php?Vии Product -57753 \\
\hline Girl Neit Door 4 for $V 4$ & littp "uw renderosity com/mod/bes indes php'Viex l'soduct-63124 \\
\hline Lcc for $\mathrm{M} 4$ & http $\because 1 w$ da $\angle 3 \mathrm{~d}$ com/1 3d-models/- m4 elite-1esture'/tem-9676\& m-d \\
\hline Maric for V4 & http uแw dd $\angle 3 \mathrm{~d}$ com $/ 1$ 3d-models/-/14-clite-tevture'tem-7674\& m-d \\
\hline Muchacho for M4 & http w 1 w renderossty con mod/bes muchacho-base-fos-m4/78491 \\
\hline Raphacl for $\mathrm{M} 4$ & http $/ /$ ww w dar3d com 1/3d-models - raplael-tor-m471tcm-10553\&_m-a \\
\hline Rio for $\mathrm{V} 4$ & hitp unw renderosity com mod/bus the-metropohtan-collection-- no-1or $14-2 / 78614$ \\
\hline Rob for $\mathrm{M} 4$ & http $/ / w \cdots$ daz $3 \mathrm{~d}$ com $1 /$ hop/itemdetals $/ 1$ tem-8928 \\
\hline Sol for M4 & htp $/ /$ ww w daz $3 \mathrm{~d}$ com $1 / 3 \mathrm{~d}$ models 1 tem-8934 \\
\hline Spartacos for M4 & hitp wilv renderosity con mod/bes index php'Vieul'soduct-80374 \\
\hline
\end{tabular}


Appendix B

Parameters for Lighting and Staging Models in Blender 2.56.

\begin{tabular}{ll}
\hline Global Parametcr & \\
\hline Anti-Aliasing & 11 \\
Resolution & $1600 \times 1000$ \\
Ambient Occlusion & 1 \\
\hline
\end{tabular}

\begin{tabular}{|c|c|c|c|c|c|c|c|c|}
\hline \multicolumn{9}{|c|}{ Light Parameters } \\
\hline & \multicolumn{3}{|c|}{ Location } & \multicolumn{3}{|c|}{ Rotation } & \multirow[t]{2}{*}{ Encrgy } & \multirow[t]{2}{*}{ Lamp Type } \\
\hline & $x$ & $y$ & $z$ & $x$ & $y$ & $z$ & & \\
\hline Light 1 & 0.39 & -0.73 & $0 . \overline{95}$ & 75.40 & -18.11 & 35.30 & 0.99 & Spotlight \\
\hline Light 2 & -0.40 & -0.81 & 0.95 & 75.61 & 52.87 & -42.64 & 0.97 & Spotlight \\
\hline Light 3 & 0.59 & 0.69 & 1.06 & 75.18 & 0.25 & 134.97 & 0.99 & Spotlight \\
\hline Light 4 & -0.07 & 1.30 & 1.13 & -67.72 & 89.72 & 25.11 & 1.00 & Hemi \\
\hline Light $5^{1}$ & -0.07 & -0.20 & 0.66 & 0.00 & 0.00 & 0.00 & 0.60 & Point \\
\hline
\end{tabular}

Note. Lights arc colourcd with $\mathrm{R} / \mathrm{G} / \mathrm{B}=1 / 1 / 1$.

'This is a "negative" light, with a Fallorr Distance of 25. 


\begin{tabular}{|c|c|c|c|c|c|c|}
\hline \multicolumn{7}{|c|}{ Camera Paramelers } \\
\hline \multicolumn{3}{|c|}{ Location } & \multicolumn{2}{|c|}{ Rotation } & & \multirow[t]{2}{*}{ Focal Length } \\
\hline$x$ & $y^{\prime}$ & 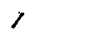 & $x$ & $!$ & ' & \\
\hline 0 & -0316 & 0698 & 89504 & 0 & 0 & $35 \mathrm{~mm}$ \\
\hline
\end{tabular}


Appendix C

Models Generated for Pre-Test

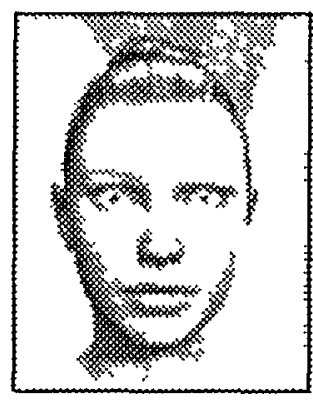

Victoria 4.2

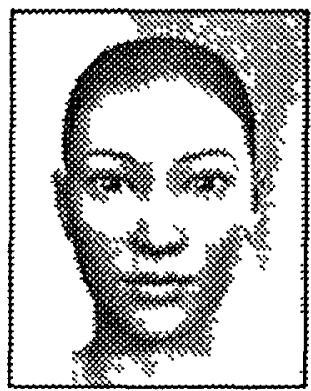

Eastern Girl

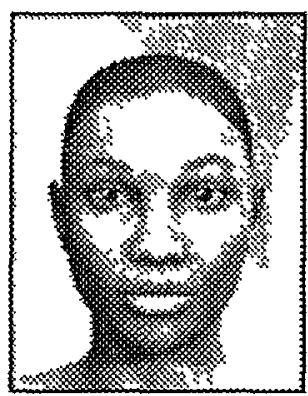

Marie

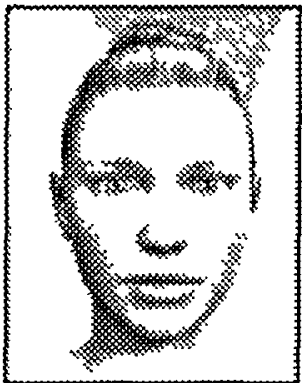

Amy

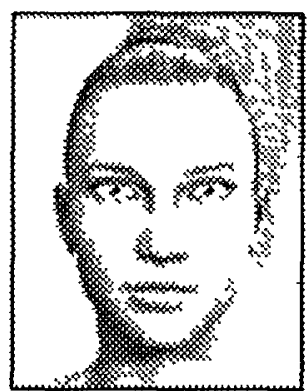

GND4

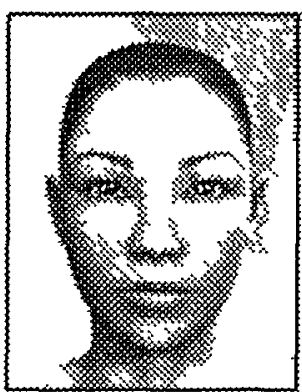

Asami

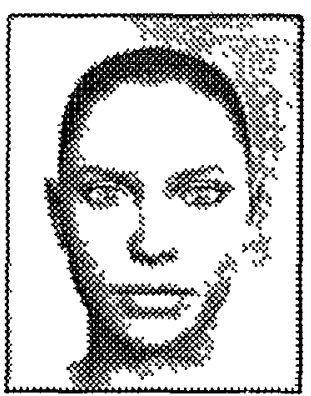

Rio

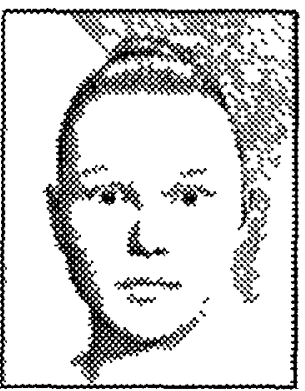

Stephanie 


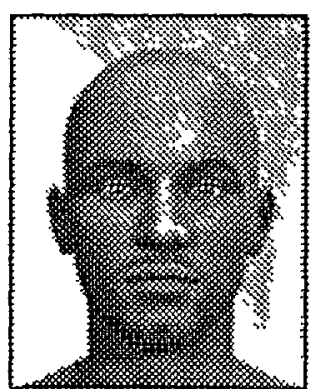

Rob

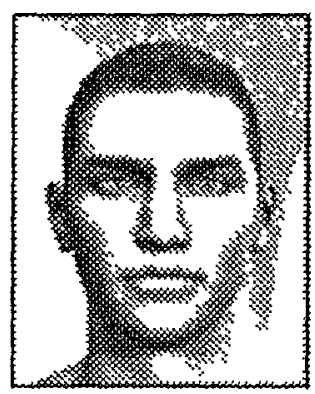

Muchacho

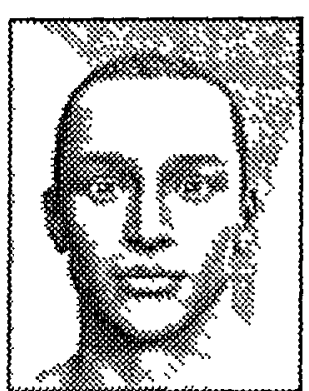

Raphael

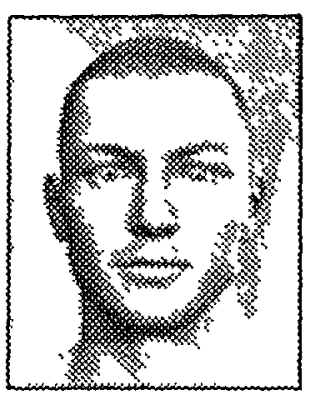

Michae: 4

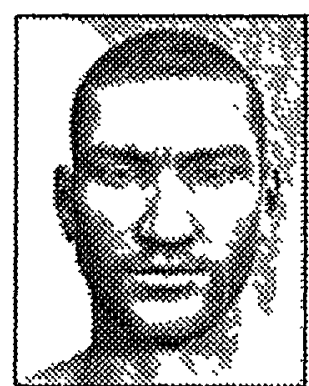

Spartacos

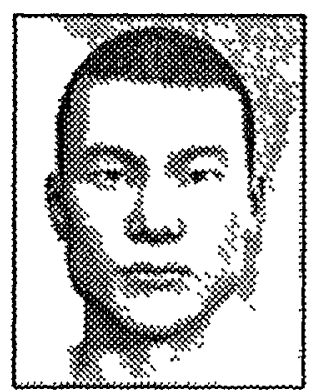

Lee

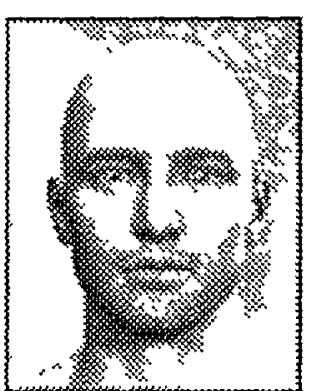

Sol

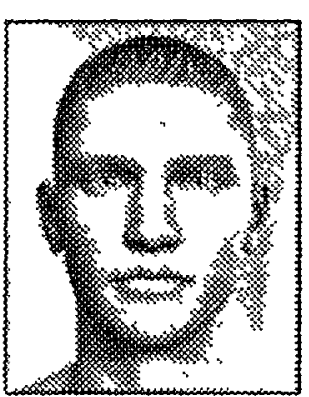

Beach Boy 
Appendix D1

Parameters for Creating Prototypicality Levels in Poser 7.

\begin{tabular}{|c|c|c|c|c|c|c|c|c|}
\hline Model & Parameter & & cality & & & & & \\
\hline \multirow[t]{8}{*}{ Male 1} & & 7 & 6 & 5 & 4 & 3 & 2 & 1 \\
\hline & FaceLong & 0 & -0.17 & -0.33 & -0.50 & -0.67 & -0.83 & -1.00 \\
\hline & Ey esIrisSizc & 0 & 0.33 & 0.67 & 1.00 & 1.33 & 1.67 & 2.00 \\
\hline & EycsHcight & () & -0.17 & -0.33 & -0.50 & -0.67 & -0.83 & -1.00 \\
\hline & EycsWidth & 0 & -0.17 & -0.33 & -0.50 & -0.67 & -0.83 & -1.00 \\
\hline & EyesSize & 0 & 0.33 & 0.67 & 1.00 & 1.33 & 1.67 & 2.00 \\
\hline & MouthHeight & 0 & -0.33 & -0.67 & -1.00 & -1.33 & -1.67 & -2.00 \\
\hline & MouthSize & () & 0.21 & 0.42 & 0.63 & 0.83 & 1.04 & 1.25 \\
\hline
\end{tabular}

Male 2

$\begin{array}{lccccccc}\text { FaceLong } & 0 & -0.17 & -0.33 & -0.50 & -0.67 & -0.83 & -1.00 \\ \text { EycsIrisSizc } & 0 & 0.33 & 0.67 & 1.00 & 1.33 & 1.67 & 2.00 \\ \text { EyesHeight } & 0 & -0.17 & -0.33 & -0.50 & -0.67 & -0.83 & -1.00 \\ \text { EycsWidth } & 0 & -0.17 & -0.33 & -0.50 & -0.67 & -0.83 & -1.00 \\ \text { EycsSizc } & 0 & 0.33 & 0.67 & 1.00 & 1.33 & 1.67 & 2.00 \\ \text { MouthHeight } & 0 & -0.33 & -0.67 & -1.00 & -1.33 & -1.67 & -2.00 \\ \text { MouthSize } & 0 & 0.21 & 0.42 & 0.63 & 0.83 & 1.04 & 1.25\end{array}$

Female 1

$\begin{array}{lccccccc}\text { FaceLong } & 0 & -0.17 & -0.33 & -0.50 & -0.67 & -0.83 & -1.00 \\ \text { EycslrisSize } & 0 & 0.04 & 0.09 & 0.13 & 0.17 & 0.22 & 0.26\end{array}$




$\begin{array}{lccccccc}\text { Ey esHeight } & 0 & -017 & -033 & -050 & -067 & -083 & -100 \\ \text { Ey esWidth } & 0 & -017 & -0.33 & -050 & -067 & -083 & -100 \\ \text { Ey esSize } & 0 & 033 & 067 & 100 & 133 & 167 & 200 \\ \text { MouthHerght } & 0 & -033 & -067 & -100 & -133 & -167 & -200 \\ \text { MouthSire } & 0 & 021 & 042 & 063 & 083 & 104 & 125\end{array}$

Female 2

\begin{tabular}{lccccccc} 
FaccLong & 0 & -017 & -033 & -050 & -067 & -083 & -100 \\
Ey csIrisSice & 0 & 004 & 009 & 013 & 017 & 022 & 026 \\
EyesHeight & 0 & -017 & -033 & -050 & -067 & -083 & -100 \\
EyesWidth & 0 & -017 & -033 & -050 & -067 & -083 & -100 \\
EyesSize & 0 & 033 & 067 & 100 & 133 & 167 & 200 \\
MouthHeight & 0 & -033 & -067 & -100 & -133 & -167 & -200 \\
MouthSize & 0 & 021 & 042 & 063 & 083 & 104 & 125 \\
\hline
\end{tabular}


Appendix D2

Parameters for the Poly Reducer Script in Blender 2.49.

\begin{tabular}{|c|c|c|c|c|c|c|c|}
\hline & & & & & & & \\
\hline Parameter & 7 & 6 & 5 & 4 & 3 & 2 & 1 \\
\hline Poly Reduce & 0 & 0.565 & 0.319 & 0.18 & 0.1 & 0.058 & 0.033 \\
\hline Boundary Weight & 0 & 9 & 9 & 9 & 9 & 9 & 9 \\
\hline Area Weight & 0 & 5 & 5 & 5 & 5 & 5 & 5 \\
\hline
\end{tabular}


Appendix D3

Polygon Counts for Each Model across Levels of Prototypicality and Realism.

\begin{tabular}{|c|c|c|c|c|c|c|c|c|}
\hline Model & Parameter & & cality & & & & & \\
\hline \multirow[t]{8}{*}{ Male 1} & & 7 & 6 & 5 & 4 & 3 & 2 & 1 \\
\hline & Facelong & 0 & -0.17 & -0.33 & -0.50 & -0.67 & -0.83 & -1.00 \\
\hline & Ey esIrisSizc & 0 & 0.33 & 0.67 & 1.00 & 1.33 & 1.67 & 2.00 \\
\hline & Ey esHcight & 0 & -0.17 & -0.33 & -0.50 & -0.67 & -0.83 & -1.00 \\
\hline & EyesWidth & 0 & -0.17 & -0.33 & -0.50 & -0.67 & -0.83 & -1.00 \\
\hline & Ey esSire & 0 & 0.33 & 0.67 & 1.00 & 1.33 & 1.67 & 2.00 \\
\hline & MouthHeight & 0 & -0.33 & -0.67 & -1.00 & -1.33 & -1.67 & -2.00 \\
\hline & MouthSize & 0 & 0.21 & 0.42 & 0.63 & 0.83 & 1.04 & 1.25 \\
\hline
\end{tabular}

Male 2

$\begin{array}{lccccccc}\text { FaceLong } & 0 & -0.17 & -0.33 & -0.50 & -0.67 & -0.83 & -1.00 \\ \text { EycsIrisSizc } & 0 & 0.33 & 0.67 & 1.00 & 1.33 & 1.67 & 2.00 \\ \text { EyesHeight } & 0 & -0.17 & -0.33 & -0.50 & -0.67 & -0.83 & -1.00 \\ \text { EyesWidth } & 0 & -0.17 & -0.33 & -0.50 & -0.67 & -0.83 & -1.00 \\ \text { EyesSizc } & 0 & 0.33 & 0.67 & 1.00 & 1.33 & 1.67 & 2.00 \\ \text { MouthHeight } & 0 & -0.33 & -0.67 & -1.00 & -1.33 & -1.67 & -2.00 \\ \text { MouthSize } & 0 & 0.21 & 0.42 & 0.63 & 0.83 & 1.04 & 1.25\end{array}$

Female 1

$\begin{array}{llllllll}\text { FaceLong } & 0 & -0.17 & -0.33 & -0.50 & -0.67 & -0.83 & -1.00 \\ \text { EyesIrisSizc } & 0 & 0.04 & 0.09 & 0.13 & 0.17 & 0.22 & 0.26\end{array}$




$\begin{array}{lccccccc}\text { Ey esHeight } & 0 & -017 & -033 & -050 & -067 & -083 & -100 \\ \text { EyesWidth } & 0 & -017 & -033 & -050 & -067 & -083 & -100 \\ \text { EyesSize } & 0 & 033 & 067 & 100 & 133 & 167 & 200 \\ \text { MouthHeight } & 0 & -033 & -067 & -100 & -133 & -167 & -200 \\ \text { MouthSi/c } & 0 & 021 & 042 & 063 & 083 & 104 & 125\end{array}$

Fcmalc 2

$\begin{array}{lccccccc}\text { FaccLong } & 0 & -017 & -033 & -050 & -067 & -083 & -100 \\ \text { EycsIrisSic } & 0 & 004 & 009 & 013 & 017 & 022 & 026 \\ \text { EyesHeight } & 0 & -017 & -033 & -050 & -067 & -083 & -100 \\ \text { EyesWidth } & 0 & -017 & -033 & -050 & -067 & -083 & -100 \\ \text { EyesSize } & 0 & 033 & 067 & 100 & 133 & 167 & 200 \\ \text { MouthHeight } & 0 & -033 & -067 & -100 & -133 & -167 & -200 \\ \text { MouthSize } & 0 & 021 & 042 & 063 & 083 & 104 & 125\end{array}$

Note The initial increase in polygons from realism levels 7 to 6 is due to the poly-reducing script which converts all quadrangles to triangles 
Appendix El

Stımul Produced for Female 2

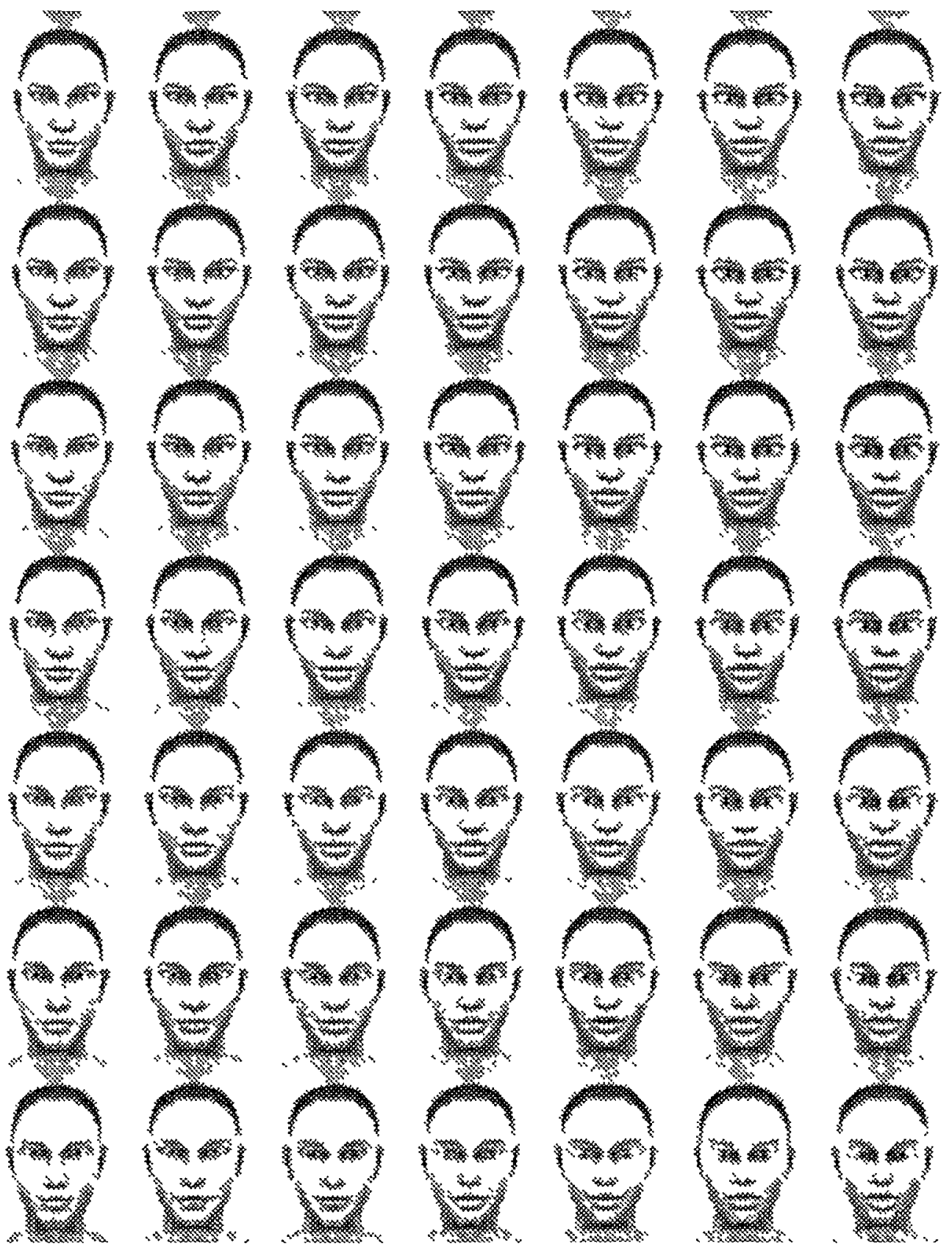


Appendix E2

Sttmul Produced for Male 1

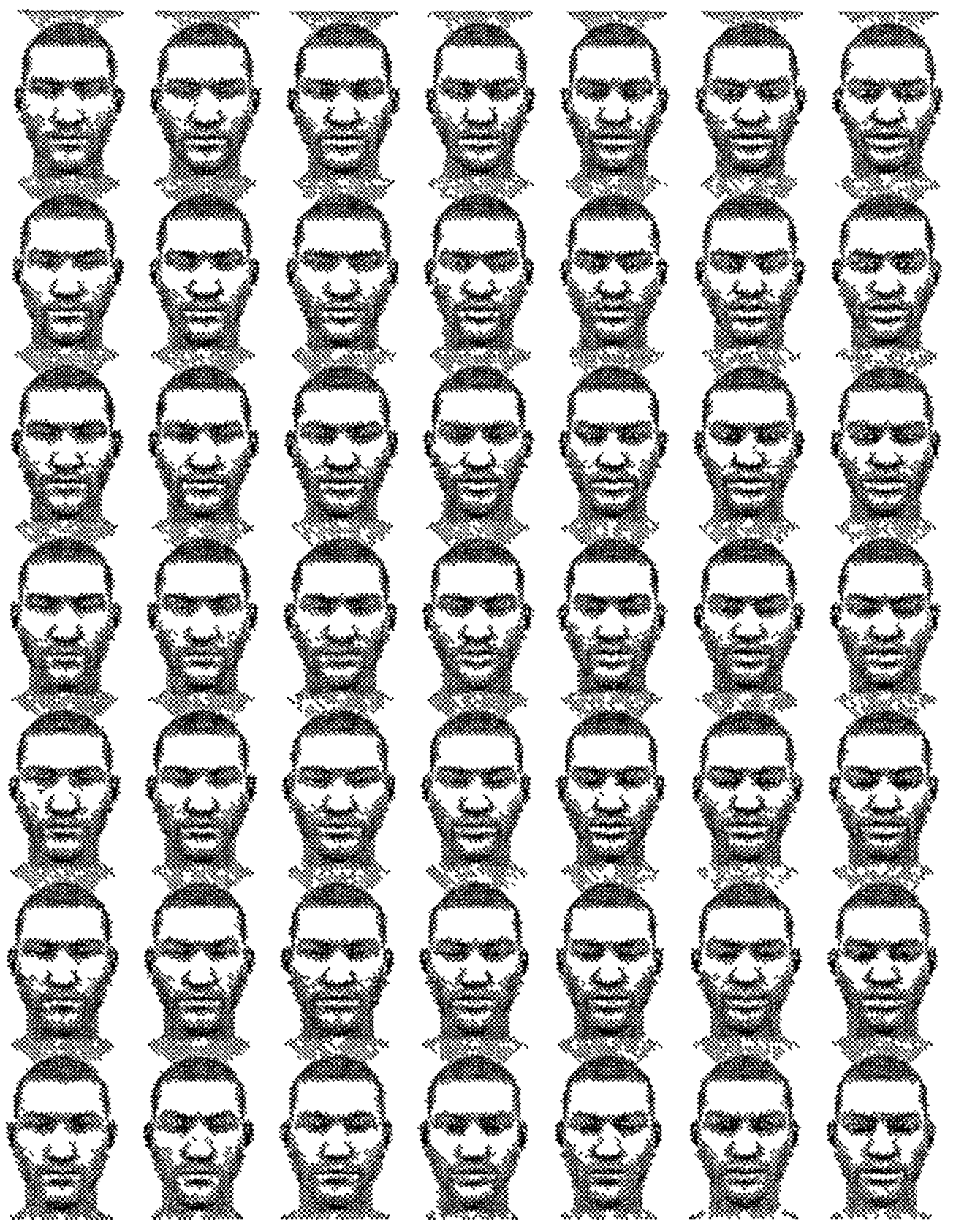


Appendıx E3

Stimull Produced for Male 2

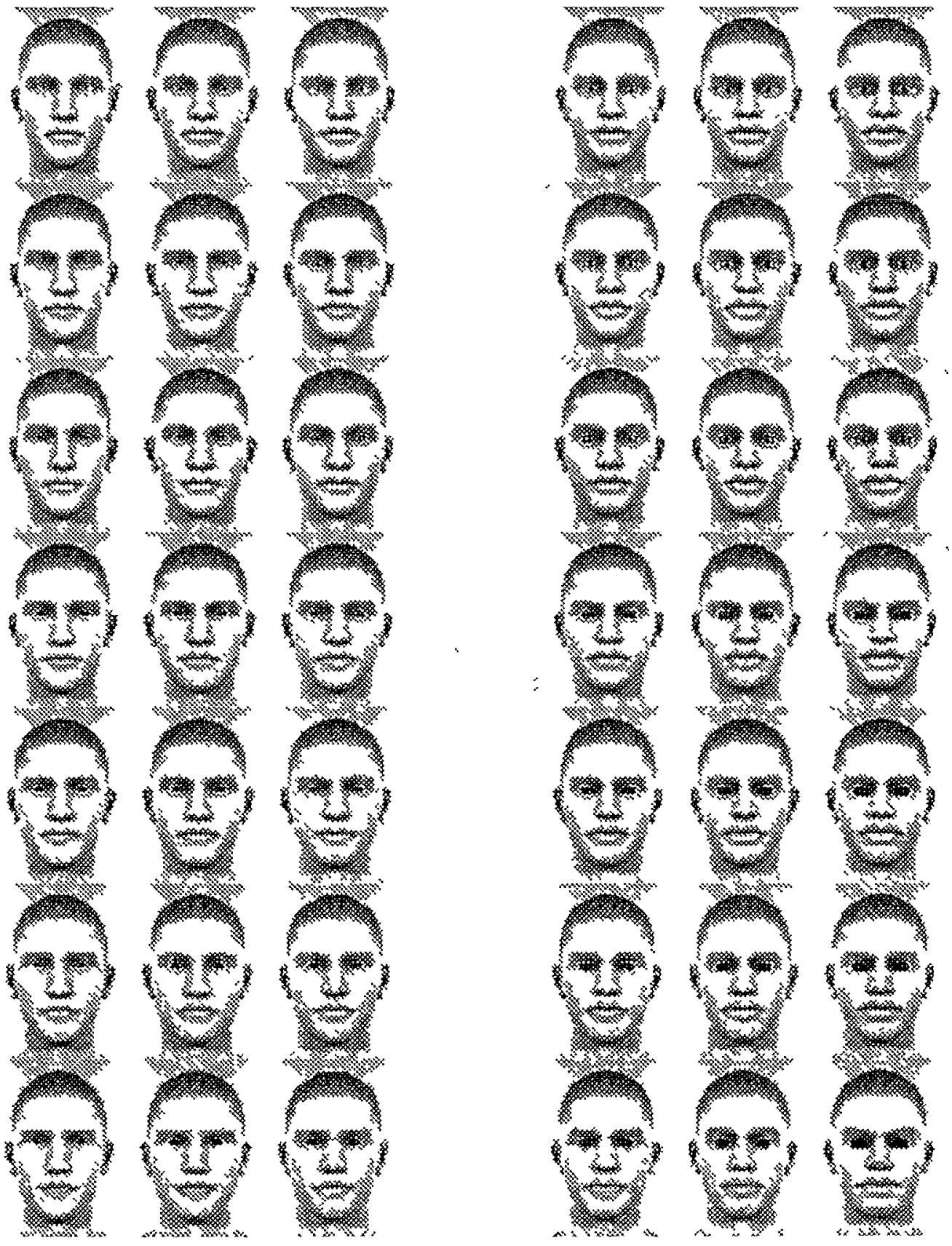

Note Column 4 corresponds to prototypicality level 4 , which is missing due to a technical error 
Appendix F1

Subjective Measurement Scales.

\section{Human Likeness:}

On a scale of $1-7$, rate the extent to which you feel that the face shown above is: HUMAN-LIKE.

\section{Eeriness:}

On a scale of $1-7$, rate the extent to which you feel that the face shown above is: EERIE.

\section{Fear:}

On a scale of $1-7$, rate the extent to which you feel that the face shown above is: SCARY.

\section{Disgust:}

On a scale of $1-7$, rate the extent to which you feel that the face shown above is: DISGUSTING.

\section{Attractiveness:}

On a scale of 1-7. rate the extent to which you feel that the face shown above is: ATTRACTIVE.

\section{Likert scale:}

1

(Not at all)
2

3

(Moderately)
5

6 7

(Extremely)

\section{Demographic questions:}

How old are you?

Please indicate your sex:

Male

Female 
Appendıx F2

Example of an Experimental Tral

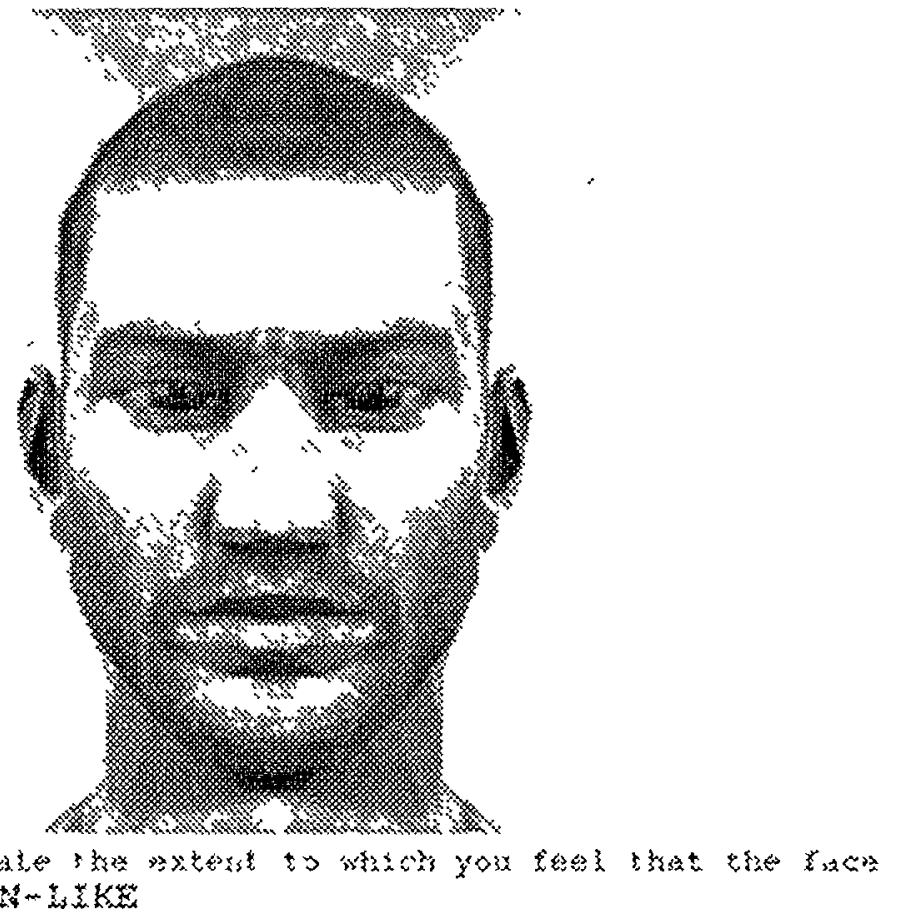

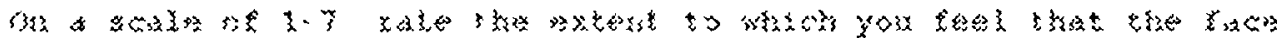

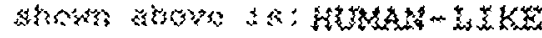

Note In this example, the face is of Male 1 at a prototypicality level of 4 , and a realism level of 1 , and the rating scale corresponds to subjective human-likeness 
Appendix F2

Informed Consent Protocol.

Purpose of study. This study aims to better understand how computer-generated human faces are emotionally evaluated at different levels of graphic quality.

Description of study. In this experiment, you will be asked to report your emotional responses to 49 female and 49 male computer-generated faces. For each face, this includes reporting your feelings of fear, disgust, and eeriness. Moreover, you will evaluate the attractiveness and human likeness of each face. You will also be asked some basic demographic questions.

Duration of study. The experiment should last no longer than 60 minutes. Compensation for your participation in this experiment will be 1.0 credit if you were recruited through the SONA system and are eligible for this bonus.

Risk and discomfort. There are no potential physical or psychological risks associated with participation in this experiment.

Anonymity. All data collected in this experiment will be kept strictly confidential through the assignment of a coded number. The information provided will be useful for research purposes only and you will not be identified by name in any reports produced from this study. Finally, the information is made available only to the researchers associated with this experiment.

Right to withdraw. You have the right to withdraw from this experiment at any time without academic penalty. Your participation in this experiment is completely voluntary. 
Appendis F4

Debrefing Protocol

What are we trying to learn from this research? When presented with a stımulus that is perceived as high in subjective human-likeness, it has been observed that it elicits negative affect (e g, MacDorman \& Ishiguro, 2006) The uncanny valley theory (Morı, 1970) suggests that low ler els of human-likeness elicit positive emotions, but that higher ler els of human-likeness elicit negative emotions Nevertheless, the evidence concerning the uncanny valley theory has been mixed Some have found support for it (e g. MacDorman \& Ishiguro, 2006, Stechenfinger \& Ghazanfar. 2009) while others have instead found that increases in human-likeness uniformly elıcit more positive emotions (e g, MacDorman, Green, Ho. \& Koch. 2009) The first purpose of this experiment was to determine the validity of this theory Negative emotions in the context of the uncanny valley is conceptualized as eerıness The phenomenology of eeriness is not partıcularly well understood, hovever One factor analysis (Ho, Pramono, \& MacDorman. 2008) observed that eenness is most strongly related to fear, disgust, and attractiveness These relationships have also received some theoretical support from MacDorman et al (2009) The second purpose of this experiment was to further examine these relationships Further. it is believed that prototypicality may also strongly predict these emotions, and by extension, predict eeriness

What are our hypotheses and predictions? We expect that the relationship betw een humanlikeness and eeriness is linear such that as human-likeness increases, affect becomes more positive It is predicted that both prototypicality and graphical realism of the computer-generated faces will explain perceived human-likeness Further, it is predicted that fear, disgust. and attractiveness will be strongly related to feelıngs of eerıness Specifically, we hypothesize that eeriness is a "complex" emotion that is composed of "basic" emotions such as fear. disgust, and attractiveness We will be testing the possibility that prototypicality elicits these basic emotions. which in turn produce eeriness

Why is this important to scientists or the general public? Since its inception in 1970, the uncanny valley theory has been accepted by designers of human-like objects, including roboticists, engineers, movie artists.anımators. and videogame designers Despite its widespread acceptance, it is still unclear whether the basic premise of the theory, the non-linear relationship between human-likeness and affect, is correct Therefore. it is important to determine the theory's validity in order to inform people working in these professions Second, eeriness is a psychological construct that is not particularly well understood Existing theories have seemed to imply that it may be "dissolved" into more well-understood affective responses such as fear, disgust, and attractiveness Empincal investigations of eeriness have not yet provided a clear picture, however If eeriness is in fact a unique phenomenon, then it may also have applications in social psychology for understanding social tolerance and stıgma 


\section{References}

Amencan Heritage Dictionary (2010a) The American Heltage Dictionary of the English Language, Fourth Editlon Retrier ed May 24, 2010, from http //ictionary reference com/browse/eerıness

Amencan Heritage Dictionary (2010b) The American Hertage Dictionary of the English Language Fourth Edition Retrieved July 20 2010. from http //dictionary reference com/browse/rapport

Amdt, J . Greenberg, J . Pyszçy nskı, T . \& Solomon. S (1997) Sublımınal exposure to deathrelated stımulı increases defense of the cultural worldview Psychological Scıence. 8(5) $379-385$

Baron. R M , \& Kenny, D A (1986) The moderator-mediator varıable distinction in social psychological research conceptual, strategic. and statıstıcal considerations Journal of Personality and Social Psychology. 51(6), 1173-82

Bartneck. C, Kanda. T. Ishiguro, H , \& Hagita, N (2007) Is the uncanny valley an uncanny cliff' In 16th IEEE International Conference on Robot \& Human Interactive Communication, 368-373 dor 10 1109/ROMAN 20074415111

Blender (Versıon 2 49) [Computer softuare] Blender Instıtute Retriered from http //www blender org/

Blender (Version 2 56) [Computer software] Blender Institute Retrieved from http //www blender org/

Bornstein. R F (1989) Exposure and affect Overview and meta-analysis of research, 19681987 Psychological Bulletm, 106(2), 265-289 do1 10 1037/0033-2909 1062265 
Brooker. D (2003) Essential CG Lightıng Techniques, 62-73 Focal Press

Burke. B L, Martens. A, \& Faucher. E H (2010) Two decades of Terror Management Theory A meta-analysis of mortality salıence research Personality and Social Psychology Review, 20(10), 1-41 do1 $101177 / 1088868309352321$

Burnham, K P. and Anderson. D R (2002) Model Selection and Multmodel Inference A Practical Information-Theoretic Approach, 63 Springer-Verlag

Chamınade, T Hodgıns, J \& Kawato. M (2007) Anthropomorphism influences perception of computer-animated characters' actions Social Cognitıve and Affective Neuroscience. 2(3), 206-216 dol 10 1093/scan/nsm017

Cohen, J (1988) Statıstıcal power analysis for the behavioral sciences (2nd ed) Routledge doi $102307 / 2283959$

Cox, C R, Goldenberg, J L , Pyszczynskı, T, \& Weıse, D (2007) Disgust. creaturelıness and the accessibility of death-related thoughts European.Journal of Social Psychology, 37(3). 494-507 do1 $101002 /$ ejsp 370

Daz 3D (n d) Daz 3d-3d software, $3 d$ models, and $3 d$ content by daz $3 d$ Retneved from http //www daz3d com

E-Prime (Version 10 ) [Computer software] Psychology Software Tools. Inc Ehman, P (1994) All emotıons are basıc In P Ekman \& R J Davidson (Eds), The Nature of Emotion Fundamental Questions, 15-19 Oxford University Press

Ellıot, A J , \& Devine, P G (1994) On the motıvational nature of cognitıve dissonance Dissonance as psychological discomfort Journal of Personalty and Social Psychology, $67(3), 382-394$ do1 $101037 / 0022-3514673382$ 
Emery. N (2000) The eyes have it the neuroethology. function and evolution of social gaze Neuroscience and Blobehavioral Reviews, 24 do1 10 1016/S0149-7634(00)00025-7

Freud S (1919) Das Unhelmlıche'[The Uncanny] Retrier ed from http //wwwrohan sdsu edu/ amtow er/uncanny html on June 22.2011

Gee, F C, Browne. W N \& Kawamura. K (2005) Uncanny valley rerisıted IEEE International Workshop on Robots and Human Interactlve Communication, 151-157 do1 10 1109/ROMAN 20051513772

Geller. T (2008) Overcoming the uncanny ralley IEEE Computer Graphics and Applications 28(4). 11-17 do1 10 1109/MCG 200879

Greenberg. J . Pyszczynskı, T, Solomon. S , \& Rosenblatt, A (1990) Evıdence for terror management theory II The effects of mortality salience on reactions to those who threaten or bolster the cultural worldview Journal of Personality and Soctal Psychology, 58(2). 308-318 do1 $101037 / 0022-3514582308$

Greenberg, J . Pyszczy nsk1, T, Solomon, S . Simon. L . \& Breus. M (1994) Role of consciousness and accessibility of death-related thoughts in mortality salience effects Journal of Personality and Social Psychology, 67(4), 627-37 do1 10 1037/00223514674627

Haıdt, J, Mccauley, C R, \& Rozın, P (1994) Individual differences in sensitıvity to disgust A scale sampling seven domans of disgust elicitors Personality and Individual Differences, 16(5), 701-713 do1 10 1016/0191-8869(94)90212-7 
Halberstadt. J (2006) The generalıty and ultimate ongins of the attractıveness of prototypes Personality and Social Psychology Revew. 10(2), 166-183 do1 $101207 / \mathrm{s} 15327957 \mathrm{pspr} 1002 \_5$

Hanel. M (2008) Transsiberian Trauns, Pain and Creepıness Vanity Falr Online Dally, Retrieved April 19, 2011, from http //www vanityfair com/onlıne/daily/2008/07/transsiberıan-trains-pain-andcreepiness html

Hanson, D (2005) Expandıng the aesthetıc possibilities for humanold robots IEEE-RAS International Conference on Humanotd Robots

Ho. C, \& MacDorman. K F (2010) Revisıtıng the uncanny valley theory Developing and valıdatıng an alternatıve to the Godspeed indıces Computers in Human Behavior, 26(6). 1508-1518 do1 $101016 / \mathrm{y}$ chb 201005015

Ho, C , Pramono, Z A \& \& MacDorman, K F (2008) Human emotion and the uncanny valley A GLM, MDS, and Isomap analysis of robot video ratıngs In Proceedings of the $3^{\prime d}$ ACM/IEEE International Conference on Human Robot Interaction. 169-176 dol $101145 / 13498221349845$

IMDB (2011) All-tıme box office world-inde Retneved on July 21, 2011 from http //www imdb com/boxoffice/alltımegross?region=world-wide

Kanwisher, N, McDermott. J \& \& Chun, M M (1997) The fusiform face area A module in human extrastriate cortex specialızed for face perception Journal of Neuroscience, 17. $4302-4311$ 
Keegan, R W (2009) The Futullst The Life and Fllms of.James Camelon Random House of Canada

Kloc. J (2009) Into the uncanny valley Seed Magazine Retrieved 2010-06-02 from $\mathrm{http} / /$ seedmagazine com/content/article/uncanny_valley

Kline. R B (2004) Principles and Practice of Structural Equatıon Modeling New York The Gulford Press

Laundau, J (Producer), \& Cameron. J (Dırector) ${ }^{*}$ (2009) Avatar [Motıon pıcture] United States $20^{\text {th }}$ Century For

Langloıs. J H (1990) Average faces are only average Psychological Sclence, 1(2). 115-121 dol $101111 / \mathrm{J} 1467-92801990$ tb00079 x

Langlois, J H , Roggman, L A . \& Musselman. L (1994) What is average and what is not average about attractive faces Psychological Science, 5(4), 214-220 dor $101111 / \mathrm{j} 1467-$ 92801994 tb00503 x

Levy. S (2004) Why Tom Hanks is less than human While sensors can't capture how humans act. humans can give life to digital characters Newsweek 144(21)

Loder. K (2004) The Polar Express is all too human MTVcom Retrieved 2010-05-31 from http //www mtv com/news/artıcles/1493616/20041110/story jhtml

MacDorman. K F (2005) Mortalıty salıence and the uncanny valley IEEE-RAS International Conference on Humanold Robots, 399-405 do1 10 1109/ICHR 20051573600

MacDorman, K F, Coram. J a, Ho. C -C . \& Patel, H (2010) Gender differences in the impact of presentational factors in human character animation on decisions in ethical dilemmas 
Presence Teleoperators and Virtual Environments. 19(3), 213-229 dol $101162 /$ pres 193213

MacDorman, K F. Green. R D . Ho, C .\& Koch, C T (2009) Too real for comfort? Uncanny responses to computer generated faces Computers in Human Behavior, 25(3). 695-710 dol 10 1016/J chb 200812026

MacDorman. K F, \& Ishiguro, H (2006) The uncanny advantage of using androids in cognitive and social science research Interachion Studies, 7(3). 297-337 dor 10 1075/1s 73 03mac

Merriam-Webster (2010) Merriam-Webster Online Dictıonary Retrieved May 24, 2010. from http //ww w merriam-w ebster com/dictıonary/eenness

Microsoft Eicel (Version 14) [Computer software] Microsoft Corporation

Mitchell, W J . Szerszen Sr, K A. Lu. A S . Schermerhorn. P W, Scheutz. M . \& MacDorman, K F (2011) A mismatch in the human realism of face and volce produces an uncanny valley 1 -Perception. 2(1), 10-12

Mon, M (1970) Bukımı no tanı [The uncanny valley] Energy. 7(4), 33-35

Myung, I (2000) The importance of complexity in model selection Jour nal of Mathematical Psychology, 44(1), 190-204 do1 10 1006/jmps 19991283

Oaten, M. Stevenson, R J , \& Case, T I (2009) Disgust as a disease-avoldance mechanısm Psychological Bullettn, 135(2), 303-21 do1 10 1037/a0014823

Park. J H , Faulkner, J . \& Schaller, M (2003) Evolved disease-avoldance processes and contemporary antı-social behavior Prejudicial attıtudes and avoıdance of people with disabilities Journal of Nonverbal Behavior, 27(2), 65-88 do1 10 1023/A 1023910408854 
Pascalıs. O, Haan. $M$ de. \& Nelson $C$ a (2002) Is face processing species-specific during the first year of life? Scıence. 296(5571) 1321-3 do1 $101126 /$ science 1070223

Peelen M V, \& Doimning. P E (2005) Selectivity for the human body in the fusiform gy rus Joul nal of Neurophysiology. 93(1), 603-8 do1 10 1152/.jn 005132004

Photoshop (Version CS4) [Computer software] Adobe

Plutchik, R (1962) The emotions Facts, theorles, and a new model Nerv York Random House Pollıck. F E (ın press) In search of the uncanny valley In K Grammer \& A Juett (Eds), Analog communication Evolution brain mechanisms, dynamics, simulation Cambndge. MA MIT Press

Poser (Version 7) [Computer software] Smith Micro Software

Ray hov. T. \& Marcoulıdes, G A (2006) A First Course in Structural Equation Modeling Newv Jersey Lawrence Erlbaum Associates

Renderosity (n d ) Renderosity - 3d models, $3 d$ content, and $3 d$ software Retrier ed from http //www renderosity com

Rhodes, G (2006) The evolutionary psychology of facial beauty Annual Revlew of Psychology, 57, 199-226 dol 10 1146/annurev psych 57102904190208

Sackett. P R . Lievens, F, Berry, C M \& \& Landers. R N (2007) A cautionary note on the effects of range restriction on predictor intercorrelations Journal of Applied Psychology. $92(2), 538-44$ do1 $101037 / 0021-9010922538$

Saygin, A P, Chamınade. T, Ishiguro. H, Driver. J . \& Frith. C (2011) The thing that should not be predictive coding and the uncanny valley in perceiving human and humanoid robot actions Social cognitıve and affective neuroscience do1 10 1093/scan/nsr025 
Schneider, E. Wang. Y \& Yang. S (2007) Exploring the uncanny valley with Japanese video game characters Proceedings of Digital Games Research Association Conference

Schneider, W, Eschman, A \& \& Zuccolotto A (2002a) E-Prime User's Gulde Pittsburgh Psychology Software Tools Inc

Schneider. W. Eschman, A, \& Zuccolotto, A (2002b) E-Prime Reference Gulde Pittsburgh Psychology Software Tools Inc

Schunn. C D . \& Wallach, D (2005) Evaluatıng goodness-of-fit in companson of models to data In W Tack (Ed), Psychologie der Kognition Reden and Vortrage anlasshch der Emertter ung von Werner Tack (pp 115-154) Saarbrueken, Germany University of Saarland Press

Seyama, J , \& Nagayama, R S (2007) The uncanny valley Effect of realism on the impression of artificial human faces Presence Teleoperators \& Virtual Environments, 16(4). 337 351 do1 $101162 /$ pres 164337

SPSS (Version 17) [Computer software] SPSS Inc, Chicago, IL

Steckenfinger, S A, \& Ghazanfar, A A (2009) Monkey visual behavior falls into the uncanny valley Proceedings of the National Academy of Sctences of the United States of America. 106(43) dol $101073 /$ pnas 0910063106

Thorrthıll, R . \& Gangestad. S W (1993) Human facıal beauty Averageness, symmetry. and parasite resistance Human Nature, 4(3), 237-269 dol 10 1007/BF02692201

Tinwell, A \& Grimshaw, M (2009) Survival horror games - an uncanny modality Games Computing and Creatıve Technologies Conference 
Tinvell. A . Grımshav. M , Nabı, D A , \& Williams, A (2011) Facial expression of emotion and perception of the Uncanny Valley in virtual characters Computers in Human Behavior. 27(2), 741-749 dol $101016 / \mathrm{J}$ chb 201010018

Tong. F, Nahayama, K, \& Moscovitch, M. Weınrıb, O .\& Kanwisher. N (2000) Response properties of the human fusiform face area Cognttve Neuropsychology, 17(1-3). 257 280 dol $101080 / 026432900380607$

Verplaetse, J , Vanneste, S . \& Braeckman. J (2007) You can judge a book by its cover the sequel A hernel of truth in predictive cheatıng detection Evolution and Human Behavior.28(4), 260-271 do1 10 1016/j erolhumbehav 200704006

Walters, G D (2004) Understandıng the popular appeal of horror cinema An integratedinteractive model Journal of Media Psychology, 9(2)

Zemeckis, R (Producer \& Director). (2004) The Polar Express [Motion picture] United States Warner Bros Pictures 